\title{
Preparation and characterization of nanocomposite PVDF ultrafiltration membrane embedded with nanoporous SAPO-34 to improve permeability and antifouling performance
}

\author{
Vahid Vatanpour ${ }^{1, *}$, Mohammad Ehsan Yekavalangi ${ }^{1}$, Mahdie Safarpour ${ }^{2}$
}

\footnotetext{
${ }^{1}$ Faculty of Chemistry, Kharazmi University, 15719-14911 Tehran, Iran

${ }^{2}$ Research Laboratory of Advanced Water and Wastewater Treatment Processes, Department of Applied Chemistry, Faculty of Chemistry, University of Tabriz, Tabriz, Iran
}

* Corresponding author:

Tel/Fax: +98 2634551023 ;

vahidvatanpour@khu.ac.ir,vahidvatanpoor@yahoo.com 


\begin{abstract}
A novel polyvinylidene fluoride (PVDF) ultrafiltration membrane blended with different concentrations of SAPO-34 nanoporous zeolite was fabricated by the non-solvent induced phase inversion method. The prepared blended membranes were characterized by scanning electron microscopy (SEM), water contact angle, porosity, energy dispersive X-ray (EDX), and permeation analyses as well as fouling and rejection tests. The SEM images of the membranes showed an asymmetric structure possessing a dense top-layer and a combination of spongy and finger-like porous sub-layer. The modified PVDF membranes had lower water contact angle, higher hydrophilicity and water flux due to the presence of hydrophilic SAPO34 zeolite in the polymer medium. All of the nanocomposite membranes showed higher flux recovery ratio $(F R R(\%))$ compared to the unfilled PVDF membrane. The membrane containing $0.5 \mathrm{wt} \%$ SAPO-34 had the best antifouling performance $(F R R=89.4 \%)$ with a bovine serum albumin (BSA) rejection value more than $99 \%$.
\end{abstract}

Keywords: Mixed matrix membranes; PVDF; SAPO-34; Zeolite; Antifouling. 


\section{Introduction}

Ultrafiltration (UF) is an efficient and energy-saving membrane filtration technique widely used in various industries such as dairy industry (milk and cheese filtration), oil-water separation, food industry (juice filtration), pretreatment for nanofiltration and reverseosmosis membranes, and protein purification [1]. The major properties of a UF membrane are its rejection, permeability, porous structure, hydrophilicity and chemical resistance [2].

One of the most widely used membrane materials is polyvinylidene fluoride (PVDF) due to its superior thermal, hydrolytic and antioxidation stability, good mechanical and membrane film forming characteristics. Nevertheless, the hydrophobic nature of PVDF has tendency to absorption of the organic constituent of feed solution and leads to its contamination by proteins and other foulants in wastewater filtration process. This contamination, which is known as membrane fouling, causes to a quick decline of pure water flux the membranes [3]. It is well established by various research projects that membrane fouling is seriously related to the surface microstructure and hydrophilicity of the membranes [4]. In recent years, great efforts have been focused on the improvement of the surface hydrophilicity and fouling resistance of the PVDF membrane to change its surface characteristics by surface modification [5-7] and blending with hydrophilic components [8-12] procedures. Especially, the modification of PVDF membranes via mixing with inorganic matters is a suitable and efficient technique for large scale applicable utilization because it could be adopted by common membrane preparation methods, i.e. the phase inversion. The presence of properly dispersed inorganic nanoparticles in the polymer body is very helpful in the enhancement of membrane permeability, control of surface characteristics of membrane and antifouling behavior [4].

Among different inorganic materials, zeolite is more common to be inserted into polymer matrix for preparation of gas separation membranes [13, 14]. The zeolites are 
microporous/nanoporous crystalline substances with uniform pore and channel size, which providing superior shape selectivity and specific sorption of gas molecules. The zeolites are aluminosilicates that have defect sites with negatively charge, which can be counterbalanced by the presence of a proton causing to the creation of Bronsted-acid sites, probably suggesting improved separation in aqueous filtration [15]. Interestingly, the zeolite could be incorporated to the polymer matrix up to $40 \mathrm{wt} \%$ of polymer without much defects in the fabrication of nanocomposite membranes in comparison to other kinds of inorganic additives [16]. The zeolites enhanced the nanoporosity and fouling resistance of reverse osmosis (RO) membranes, and caused an improvement in permeability and salt rejection particularly for seawater desalination [17].

SAPO-34 is a silicoaluminophosphate zeolite with a composition of $\mathrm{Si}_{\mathrm{x}} \mathrm{Al}_{\mathrm{y}} \mathrm{P}_{\mathrm{z}} \mathrm{O}_{2}$, where $\mathrm{x}=0.01-0.98, \mathrm{y}=0.01-0.60$, and $\mathrm{z}=0.01-0.52$. The SAPO-34 structure is constructed by replacement of silicon for phosphorous in the $\mathrm{AlPO}_{4}$, that forms a neutral framework and shows no ion exchange capacity [17]. The SAPO-34 nanoporous particles were characterized by the hydrophilic framework and high pore volume, representing the high water adsorption and fast water diffusion within the nanostructure, and consequently the high water flux [19]. Most of the SAPO-34 membrane studies have been focused on separating $\mathrm{CO}_{2}$ from $\mathrm{CH}_{4}$ [1824] and there is rare investigation of SAPO-34 on the modification of the UF or MF (microfiltration) membranes. It is attractive to incorporate the nanoporous SAPO-34 framework in the matrix of membranes, which improves the filtration performance [25]. Liu et al. [26] were prepared a thin film nanocomposite (TFN) hollow fiber membrane containing nanoporous SAPO-34 nanoparticles on the dual-layer (PES/PVDF) hollow fiber substrate. Compared to the NF-90, the TFN (DOX) membrane simultaneously improved the water flux and the rejections. 
To the best of our knowledge, there is no study on the modification of PVDF ultrafiltration membranes using SAPO-34. The objective of the present study is to develop SAPO-34 blended PVDF membrane with the aim to obtain fouling mitigation and permeability augmentation. The influence of the SAPO-34 amount in the matrix of the membrane on the performance of the prepared nanocomposite membranes was investigated.

\section{Experimental}

\subsection{Materials}

Zeolite SAPO-34 (molar ratio of P:Si:Al = 1:1:0.4, $\rho=0.75 \mathrm{~g} / \mathrm{cm}^{3}$ ) particles [28] were dedicated from Research Institute of Petroleum Industries, Iran. Polyethylene glycol (PEG) polymer with average molecular weight of $4000 \mathrm{~g} / \mathrm{mol}$ and bovine serum albumin (BSA, $\left.\mathrm{M}_{\mathrm{W}}=67,000\right)$ were purchased from Merck. DMAc and PVDF were obtained from BASF and Alfa Aesar Co., respectively.

\subsection{Preparation SAPO-34/PVDF membranes}

The SAPO-34 blended nanocomposite PVDF membranes were fabricated by the phase inversion method using PVDF as a bulk material, DMAc as a solvent, the SAPO-34 as an inorganic additive and distilled water as a non-solvent. Briefly, different amounts of SAPO$34(0,0.1,0.2,0.5,1.0,2.0$ and $5.0 \mathrm{wt} \%$ based on the weight of PVDF) were mixed to the DMAc and were sonicated for $2 \mathrm{~h}$. Next, PVDF (18 wt $\%$ ) and PEG (1 wt $\%$ ) were added to the above solutions and magnetically stirred for $48 \mathrm{~h}$ at $70{ }^{\circ} \mathrm{C}$. The obtained homogenous solutions were kept in a drying oven for $24 \mathrm{~h}$ at $50{ }^{\circ} \mathrm{C}$ to be degassed. Finally, the solutions were cast on glass plates using a doctor blade knife with specific casting rate and thickness of $150 \mu \mathrm{m}$. Then, the cast films were dipped in $\mathrm{RO}$ water at $25^{\circ} \mathrm{C}$ as a coagulation bath. The 
resulted membranes were washed with $\mathrm{RO}$ water to eliminate the remaining solvent and kept in RO water until using.

\subsection{Characterization}

Scanning electron microscope (SEM) (Tescan, Czech Republic) was used to investigate the surface morphology of the SAPO-34 and prepared membranes. To prepare cross-section samples, the membranes were frozen in liquid nitrogen and fractured. Next, they were coated with gold to obtain conductive samples.

X-ray diffraction (XRD) pattern of SAPO-34 was measured by a Siemens X-ray diffraction D5000 diffractometer (Germany), with $\mathrm{Cu} K \alpha$ radiation (1.54065 A). The static water contact angle of the membrane surface was measured with a goniometer (G10, Kruss, Germany) at $25{ }^{\circ} \mathrm{C}$ and a relative humidity of $45 \%$ according to sessile-drop method. The average of contact angle values of five random locations was reported as the contact angle to minimize the experimental errors. To estimate the overall porosity of the membranes $(\varepsilon)$, the gravimetric method was applied. The used equation is presented in the Eq. (1) [27]:

$\varepsilon=\frac{\omega_{1}-\omega_{2}}{A \times l \times d_{w}}$

In this equation, $\omega_{1}$ and $\omega_{2}$ are the weights of the wet and dry membranes, respectively; $A, l$ and $d_{w}$ are the membrane area $\left(\mathrm{m}^{2}\right)$, thickness $(\mathrm{m})$ and water density $\left(0.998 \mathrm{~g} / \mathrm{cm}^{3}\right)$, respectively.

\subsection{Membrane permeation and antifouling performance}

The permeation flux and antifouling tests of the SAPO-34/PVDF membranes were performed using a dead-end experimental system with effective membrane area of $19.6 \mathrm{~cm}^{2}$. Any membrane was pre-compacted at $0.5 \mathrm{MPa}$ for $20 \mathrm{~min}$ to achieve a stable flux of pure water. 
All of the tests were performed at feed pressure of $0.3 \mathrm{MPa}$. The pure water flux of the membranes was recorded every $5 \mathrm{~min}$ for $90 \mathrm{~min}$, and at least 6 replicates were done to obtain an average value. The permeation flux was calculated using following equation:

$$
J_{w, l}=\frac{M}{A t}
$$

where $M, A$ and $t$ are the weight of the collected permeates $(\mathrm{kg})$, the membrane effective area $\left(\mathrm{m}^{2}\right)$ and the permeation time $(\mathrm{h})$.

The antifouling property of the SAPO-34/PVDF membranes was evaluated by flux recovery ratio $(F R R)$ parameter using the subsequent method: after the pure water test $\left(J_{w, 1}\right), 500 \mathrm{mg} / \mathrm{L}$ BSA solution was instantly replaced in the filtration cell and the BSA solution flux, $J_{p}\left(\mathrm{~kg} / \mathrm{m}^{2}\right.$ h) was measured based on the collected water weight at $0.3 \mathrm{MPa}$ for $90 \mathrm{~min}$. After that, the membranes were immersed in a water bath for $20 \mathrm{~min}$ and their pure water flux were recorded again, $J_{\mathrm{w}, 2}\left(\mathrm{~kg} / \mathrm{m}^{2} \mathrm{~h}\right)$. The $F R R$ value of the membranes was calculated using Eq. 3 to investigate the antifouling performance.

$$
\operatorname{FRR}(\%)=\left(\frac{J_{w, 2}}{J_{w, 1}}\right) \times 100
$$

Also, fouling resistance parameters including total fouling ratio $\left(R_{t}\right)$, reversible fouling ratio $\left(R_{r}\right)$ and irreversible fouling ratio $\left(R_{i r}\right)$ were calculated to study the fouling of the membranes process in detail using the following equations:

$$
\begin{aligned}
& R_{t}=\left(1-\frac{J_{p}}{J_{w .1}}\right) \times 100 \\
& R_{r}=\left(\frac{J_{w, 2}-J_{p}}{J_{w, 1}}\right) \times 100 \\
& R_{i r}=\left(\frac{J_{w, 1}-J_{w, 2}}{J_{w, 1}}\right) \times 100
\end{aligned}
$$


In these equations, $R_{r}$ represents the fouling resulted by concentration polarization and $R_{i r}$ shows the fouling caused by adsorption/deposition of protein molecules on the membrane surface. $R_{t}$ is the sum of $R_{r}$ and $R_{i r}$ and indicates the scale of total flux decline caused by total fouling [27].

The rejection performance of the membranes was also investigated using permeate samples taken at the end of BSA filtration. The UV-Vis spectrophotometer (Hach DR 2000, USA) was applied to measurement the concentration of BSA in the feed and permeate sample. The rejection, $R$, was calculated by Eq. 7:

$R(\%)=\left(1-\frac{C}{C_{0}}\right) \times 100$

$R$ is the BSA rejection (\%), $C$ and $C_{0}$ are the concentration of BSA in the permeate and feed solution (mg/L), respectively.

\section{Results and discussion}

\subsection{Characterization of SAPO-34}

The XRD pattern of the SAPO-34 zeolite is shown in Fig. 1. The appeared sharp peaks in this pattern indicate the excellent crystalline structure of the SAPO-34. The strong observed peaks at $2 \theta$ of 9.7 and $20.6^{\circ}$ are characteristic peaks of the SAPO-34 that are well matched with literature $[28,29]$.

Fig. 2 shows the SEM images of the SAPO-34 sample at two different magnifications. These images depict the neat cubic shape of the SAPO-34 with a dimensions around 1-6 $\mu \mathrm{m}$. It is known that the synthesis and handling of nanostructures is more difficult and sensitive than microstructures. So, it would be very important if can use the advantages of more practicable and easy-handling materials with higher scale up and development possibility. 


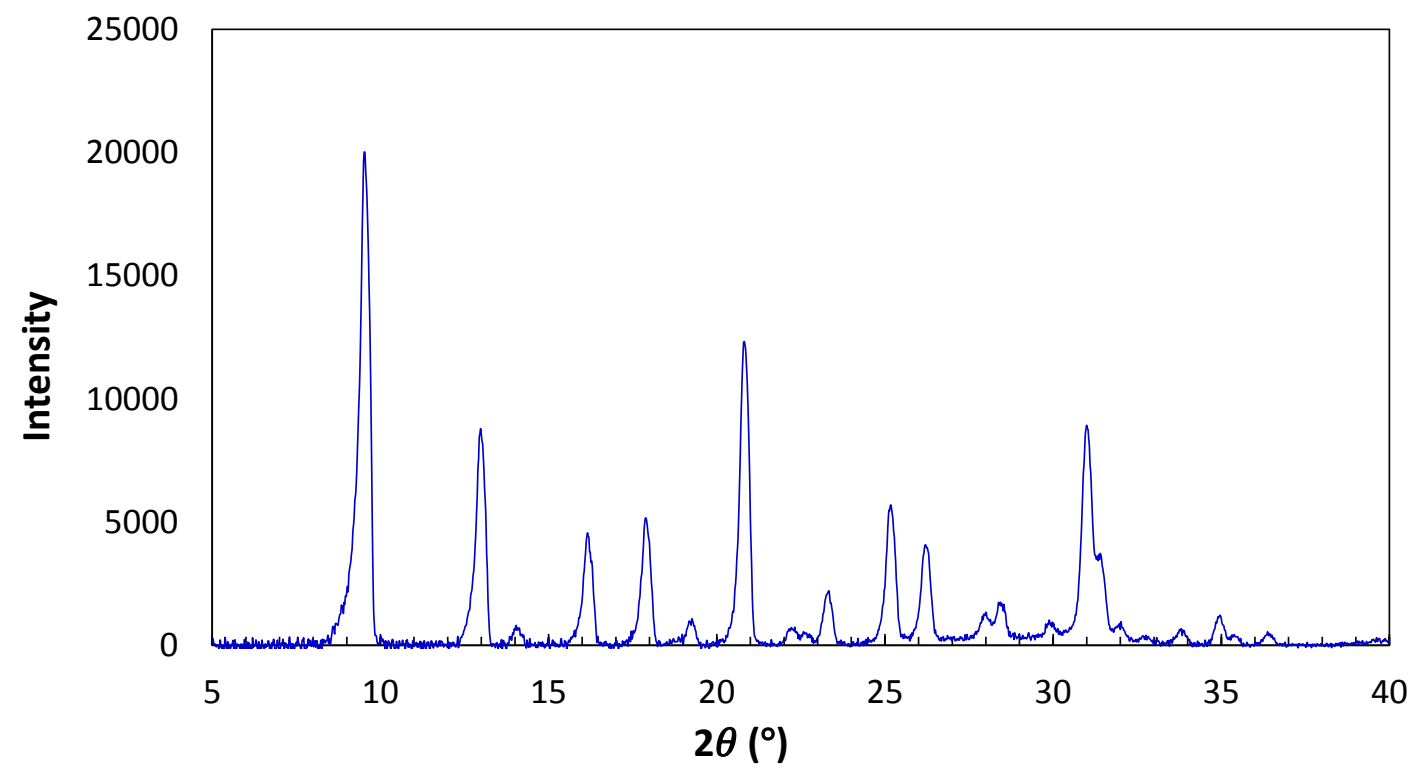

Fig. 1. XRD pattern of SAPO-34.

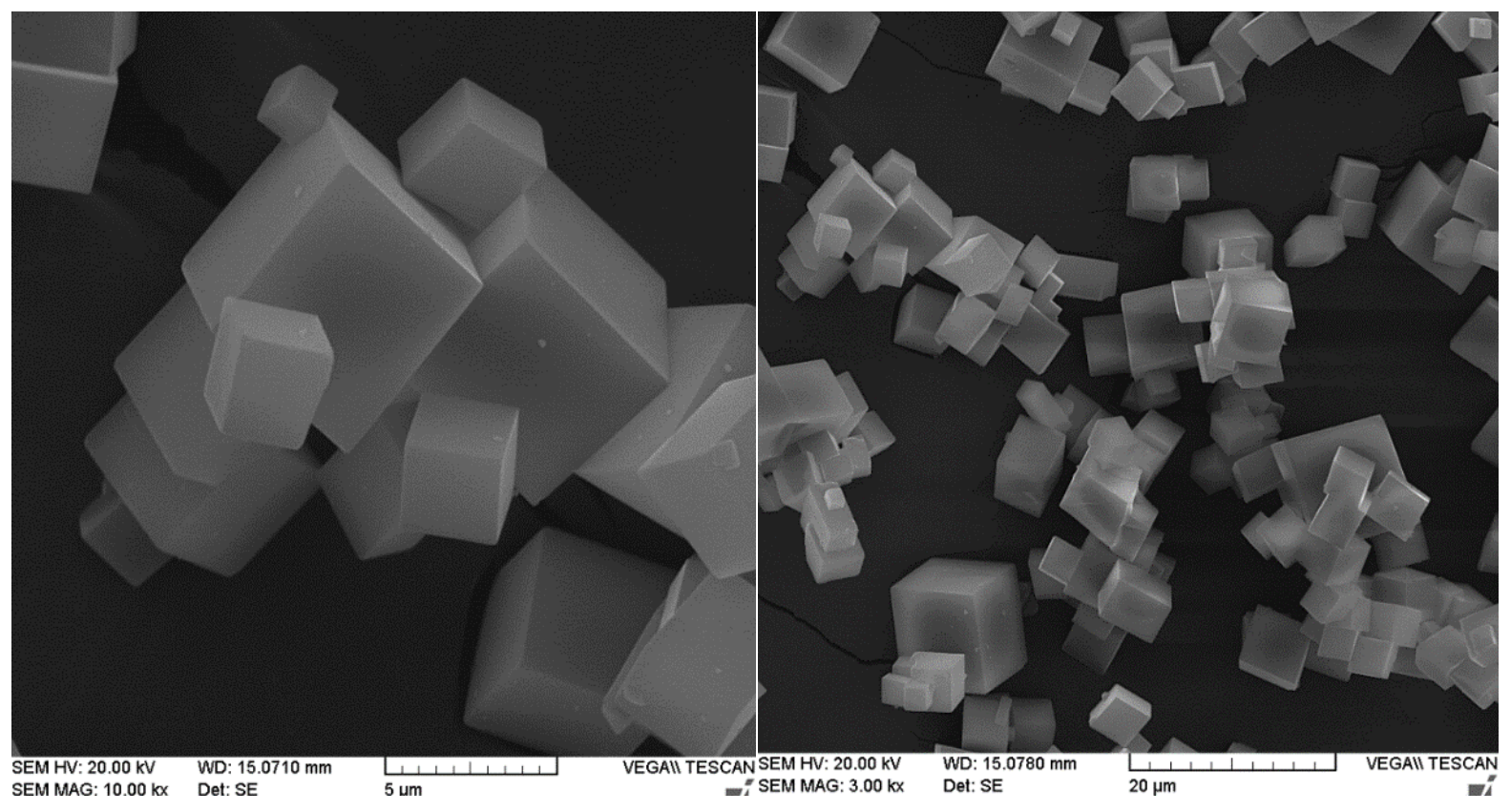

Fig. 2. SEM images of SAPO-34.

\subsection{Characterization of membranes}




\subsubsection{Surface characteristics of the SAPO-34/PVDF membranes}

SEM analysis was used to investigate the effect of different concentrations of the SAPO-34 on the microstructure of the PVDF membranes. Fig. 3 displays SEM images from the surface of the prepared membranes. As can be seen, the surface of the fabricated membranes is relatively smooth and the inorganic additive (SAPO-34) mass or lump is not observed in the surface (a little lump is appeared on the surface of the $5 \mathrm{wt} \%$ membrane). Also, no cracks are observed on the surface of the membranes, indicating that they did not become brittle by the addition of the SAPO-34 zeolite.

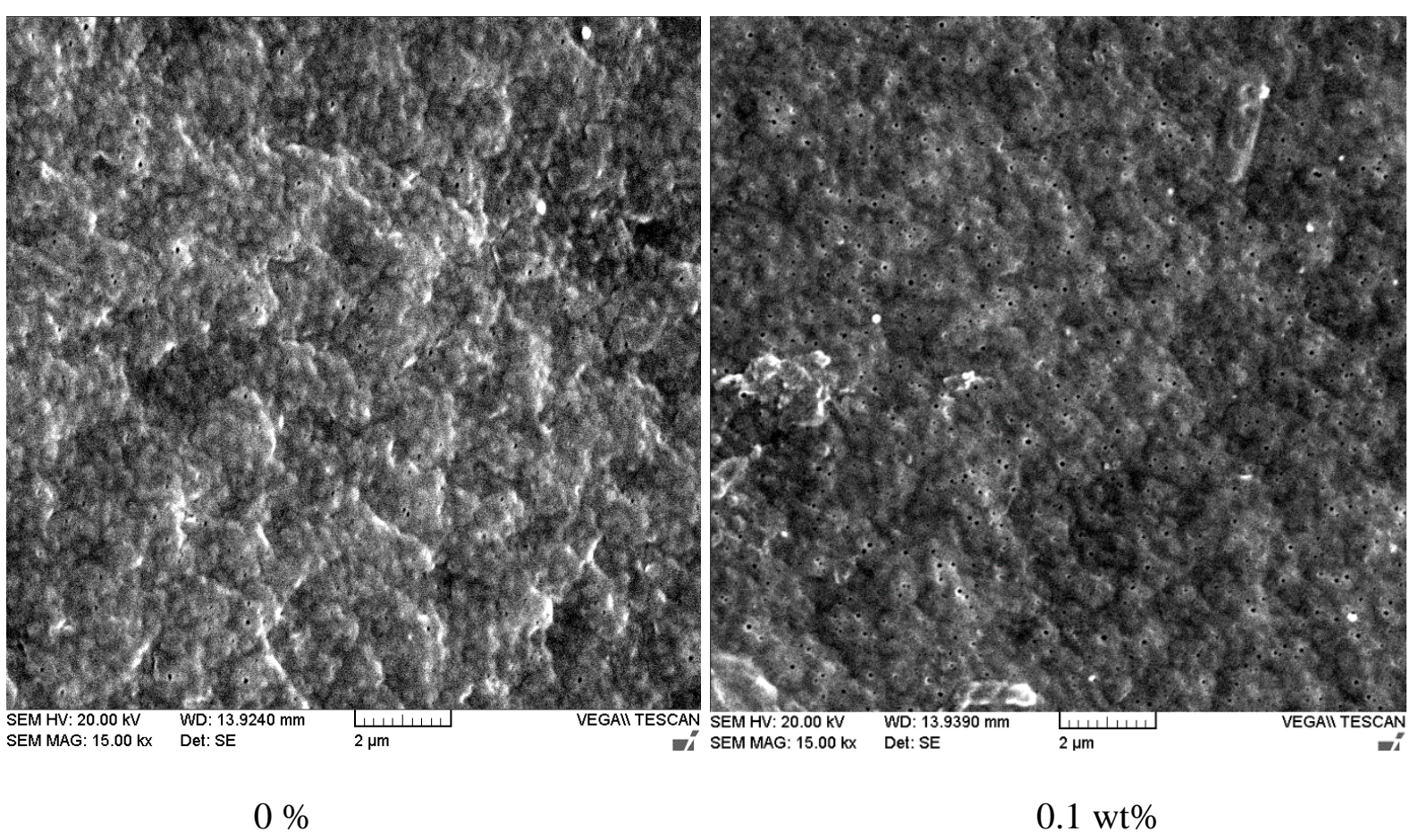



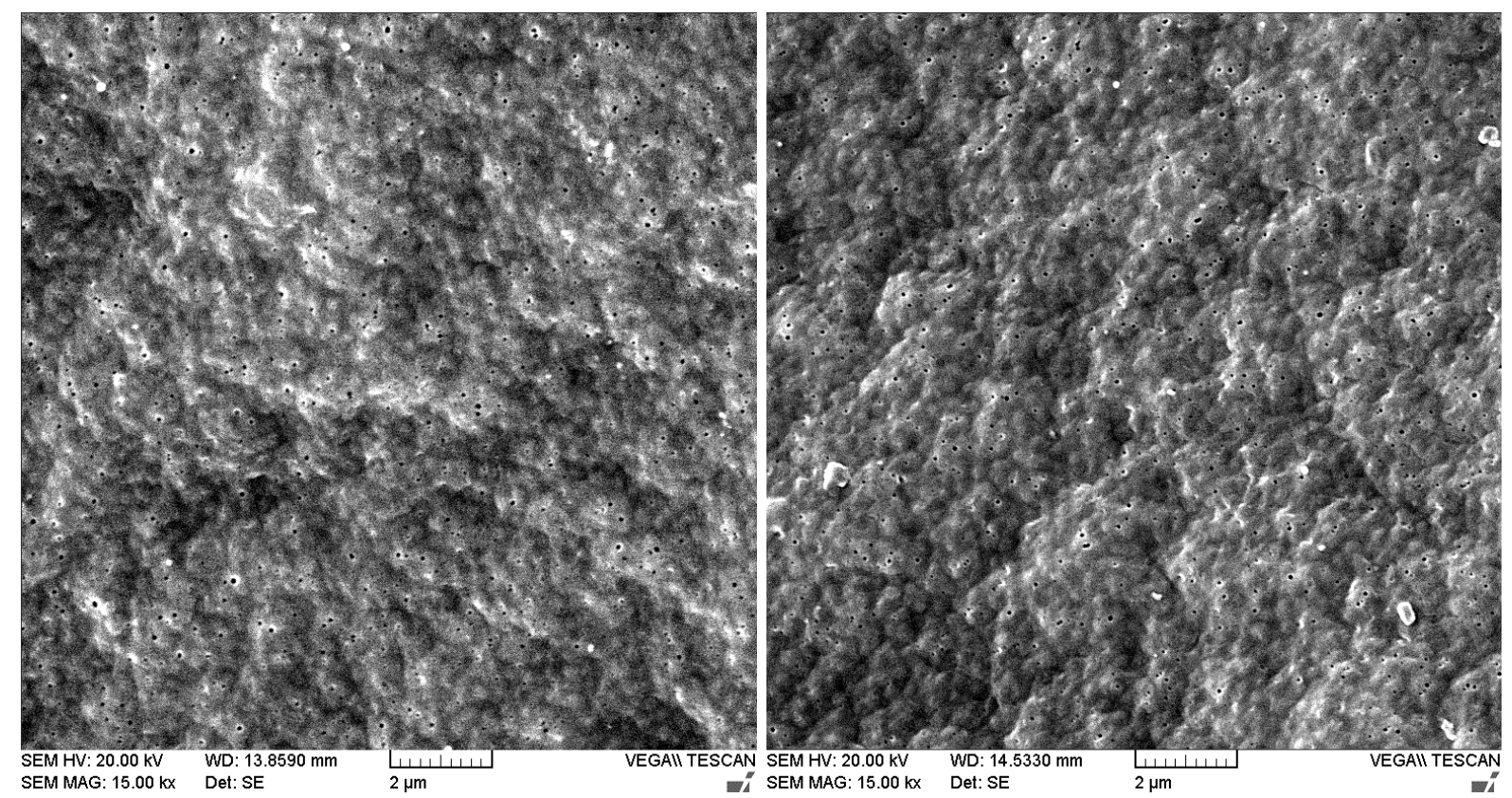

$0.2 \mathrm{wt} \%$

$0.5 \mathrm{wt} \%$
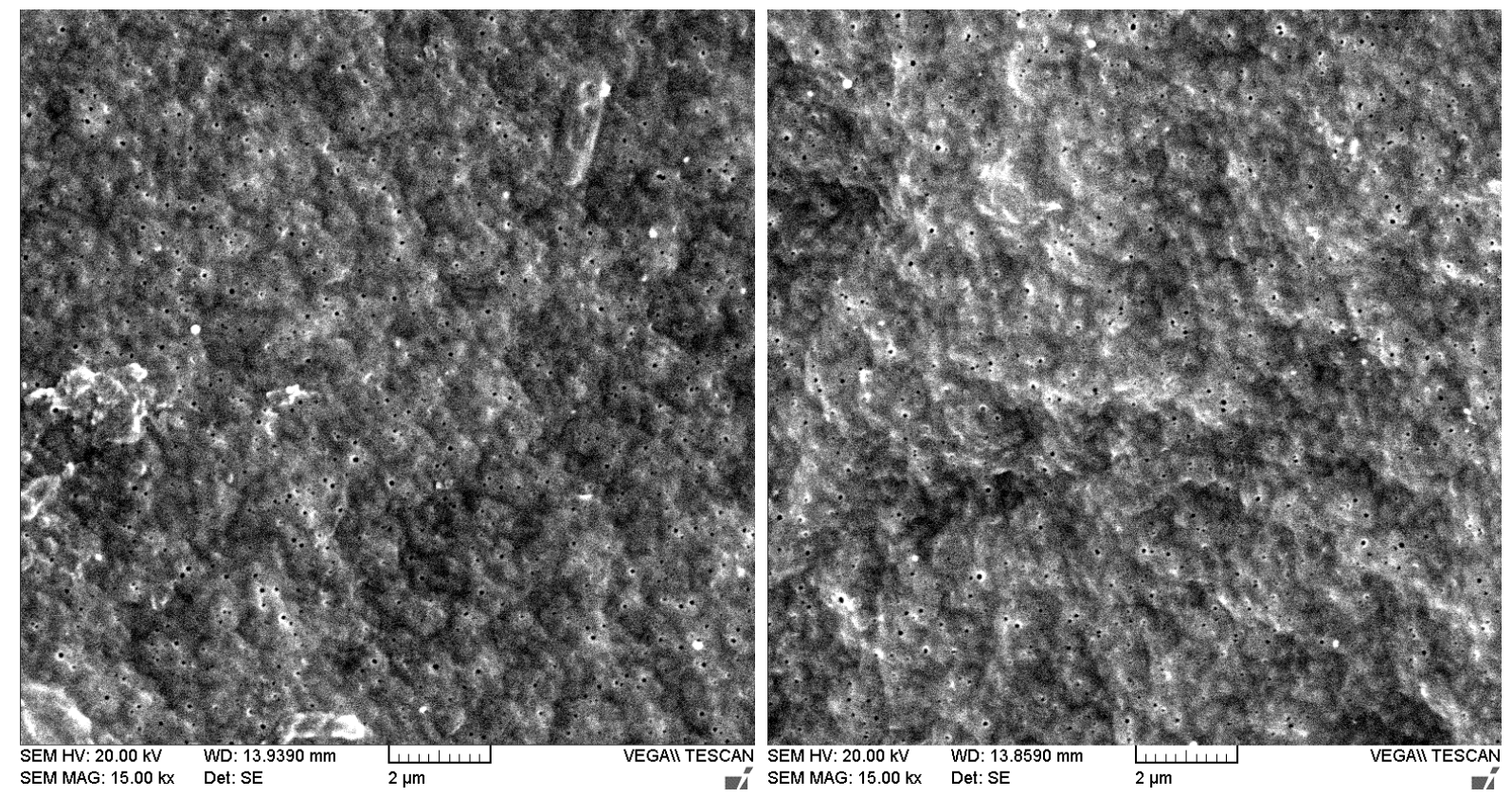

$1.0 \mathrm{wt} \%$

$2.0 \mathrm{wt} \%$ 


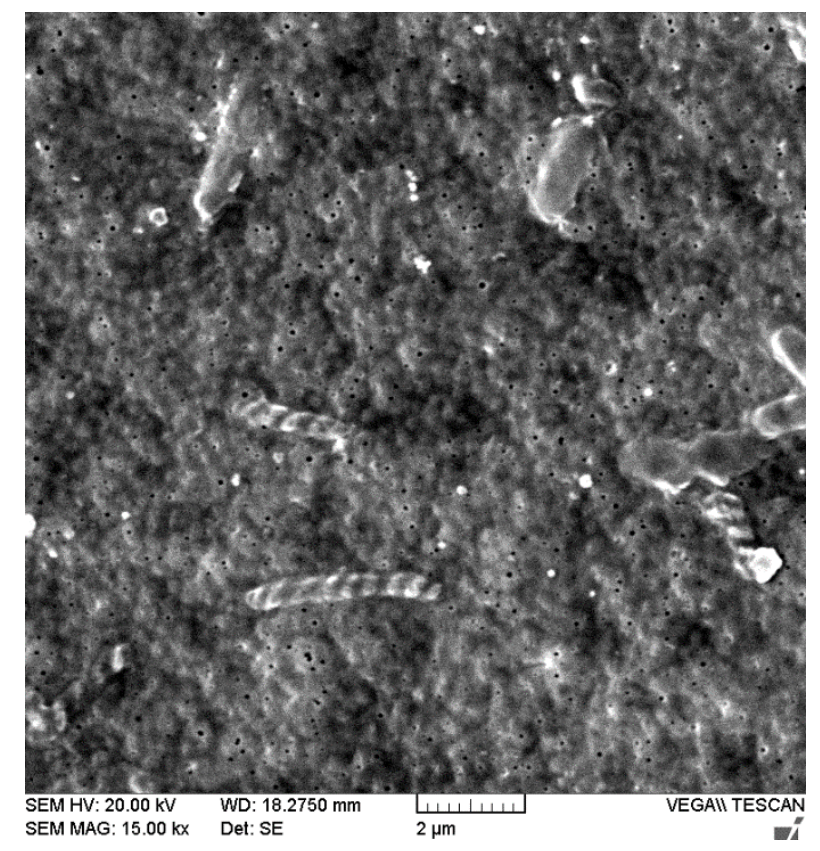

$5 \mathrm{wt} \%$

Fig. 3. Surface SEM images of the prepared PVDF membranes with different concentrations of SAPO-34.

The cross-sectional SEM images of the fabricated membranes with different SAPO-34 contents are shown in Fig. 4. As shown, the PVDF membranes presented asymmetric structure including a dense top-layer and a combination of spongy and finger-like porous sublayer. It can be observed that there is no significant difference between the structure of the blended and bare PVDF membranes indicating that the membrane formation was not influenced notably by the addition of SAPO-34 during the phase inversion. The bottom spongy and relative dense layer of the membranes are more preferable for water separation functions, as the existence of macrovoids in the structure of membrane is undesirable because the macrovoids might have opposed effect on stability of the membranes in long-term application $[30,31]$. 


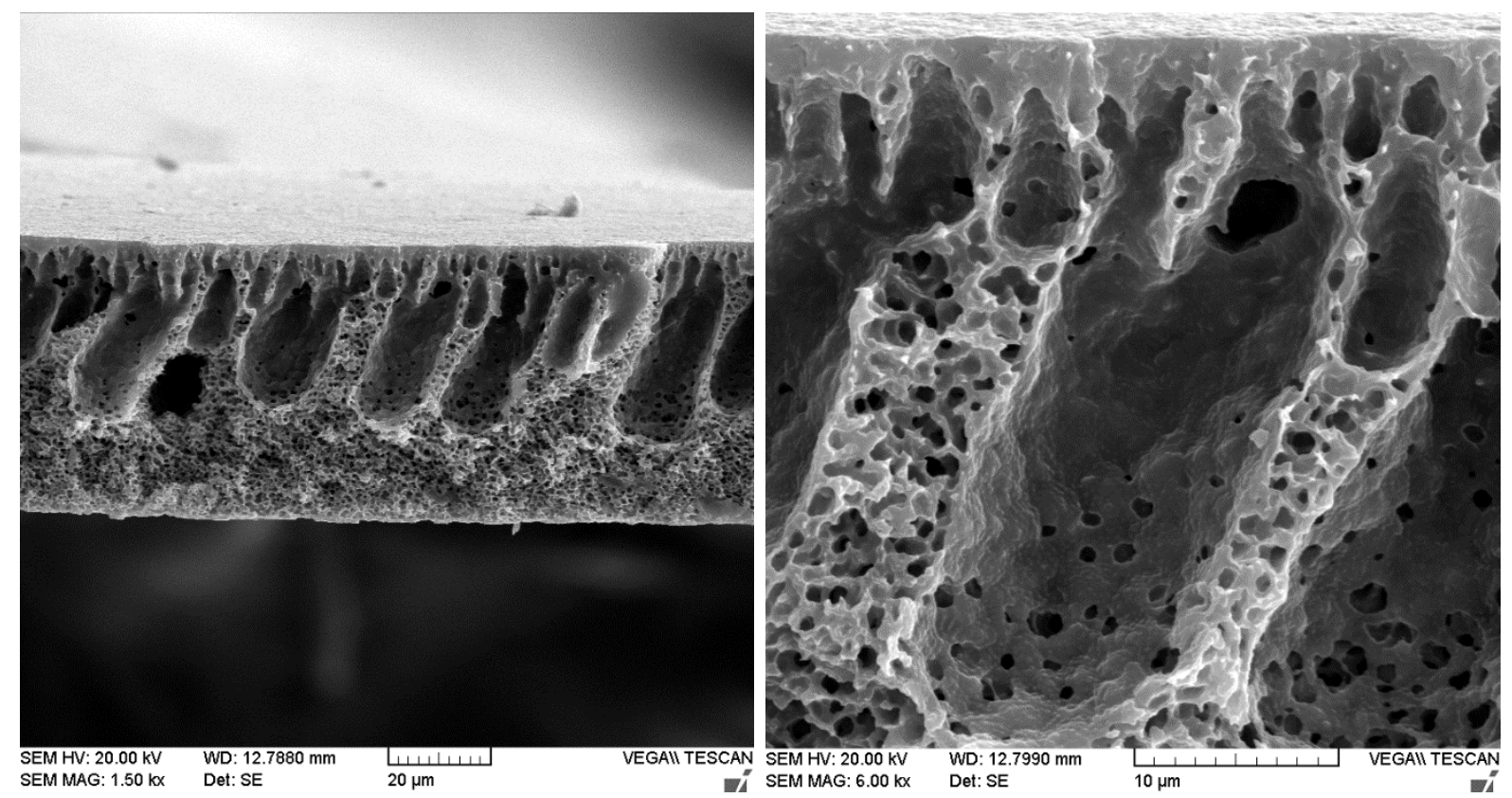

$0 \mathrm{wt} \%$

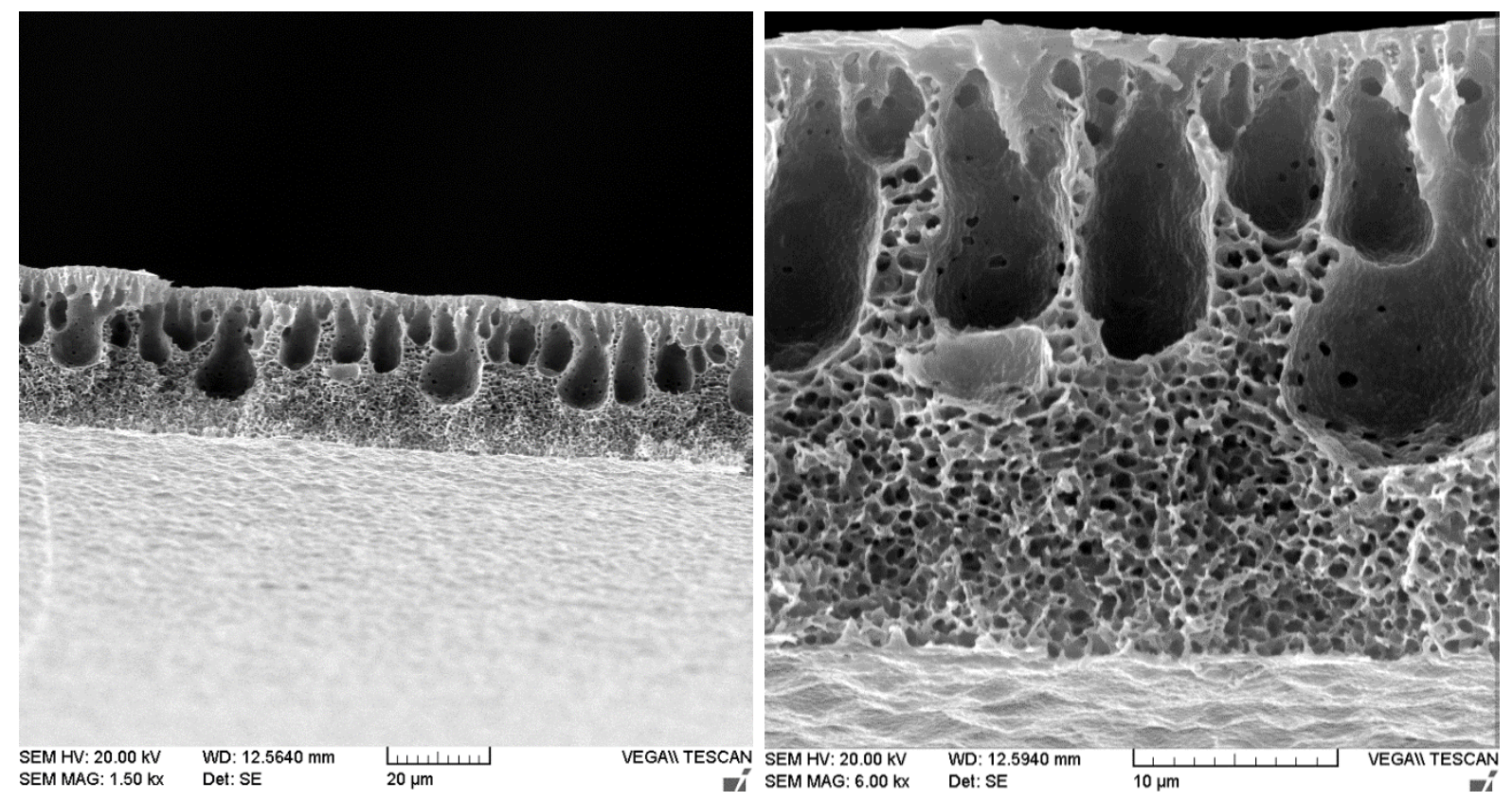

\section{$0.1 \mathrm{wt} \%$}




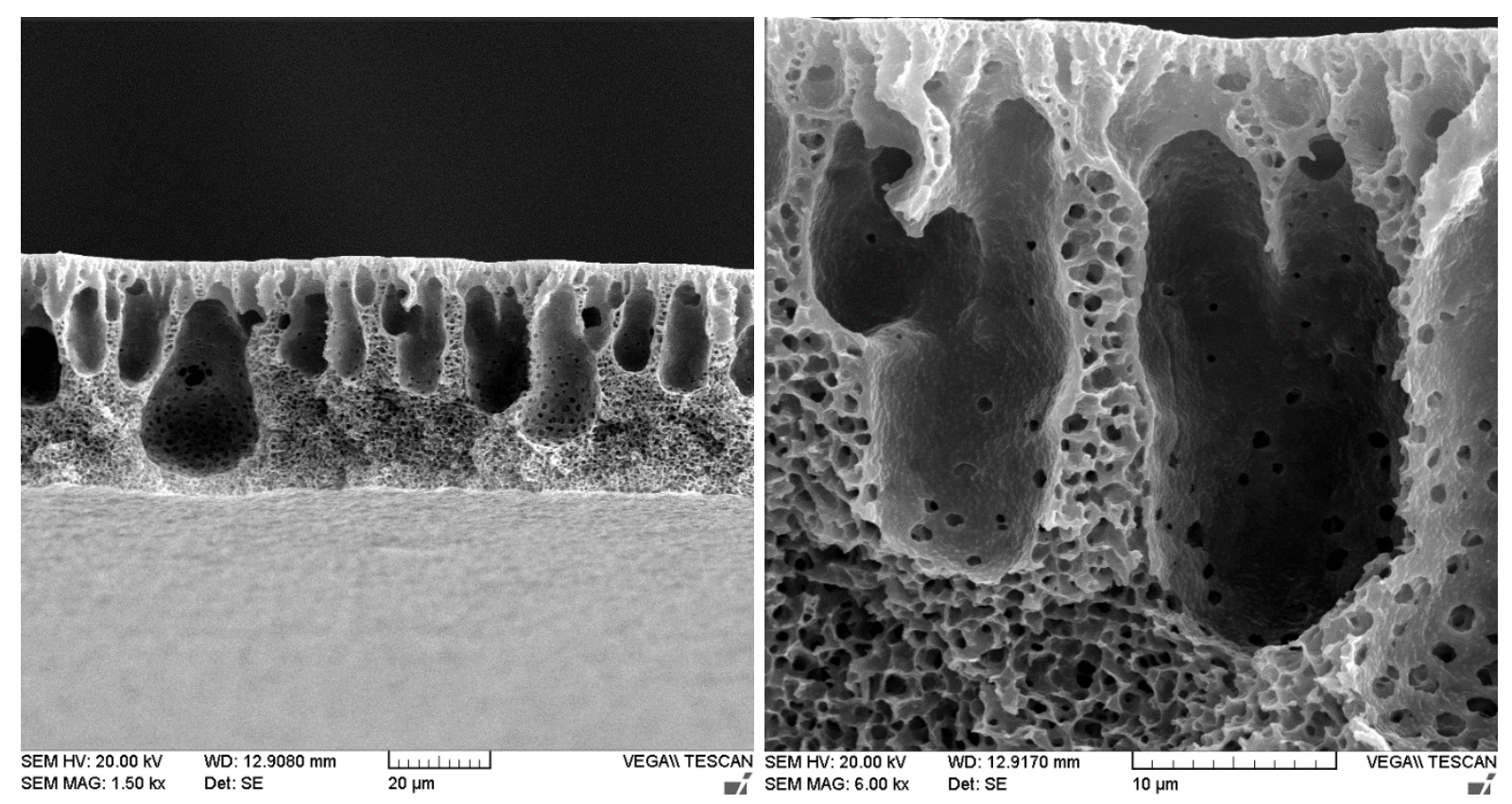

$0.2 \mathrm{wt} \%$

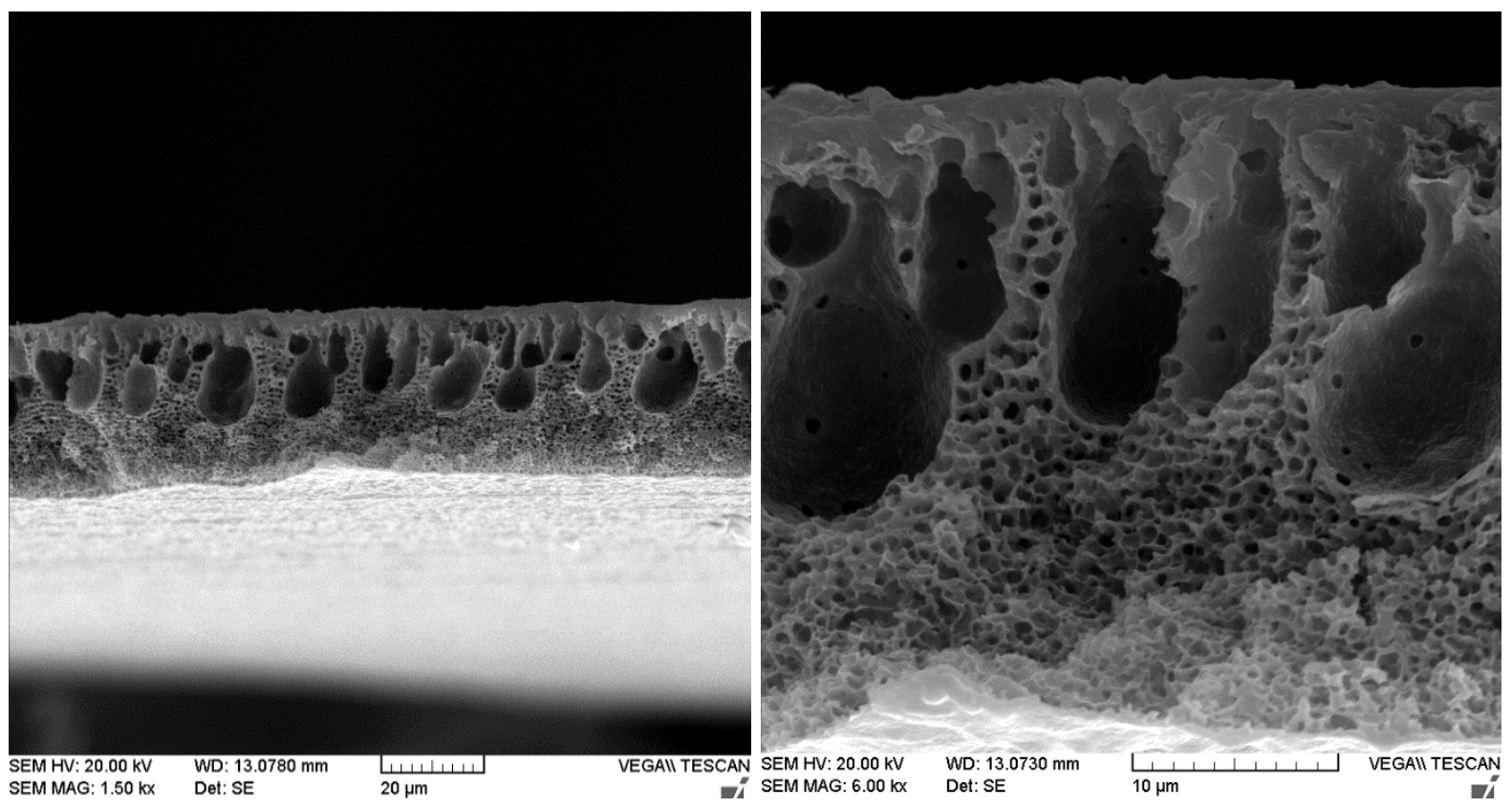

$0.5 \mathrm{wt} \%$ 


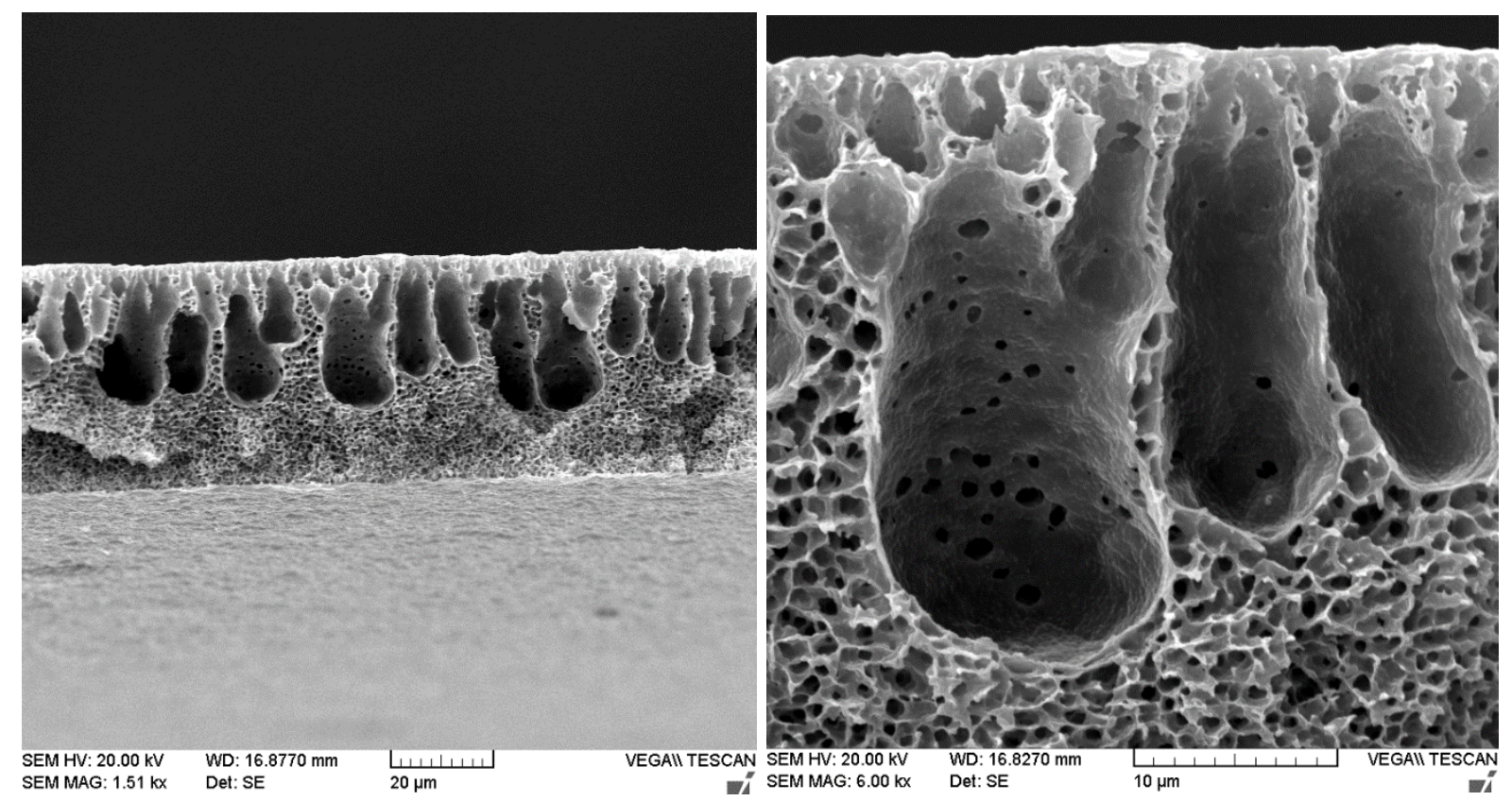

$1.0 \mathrm{wt} \%$
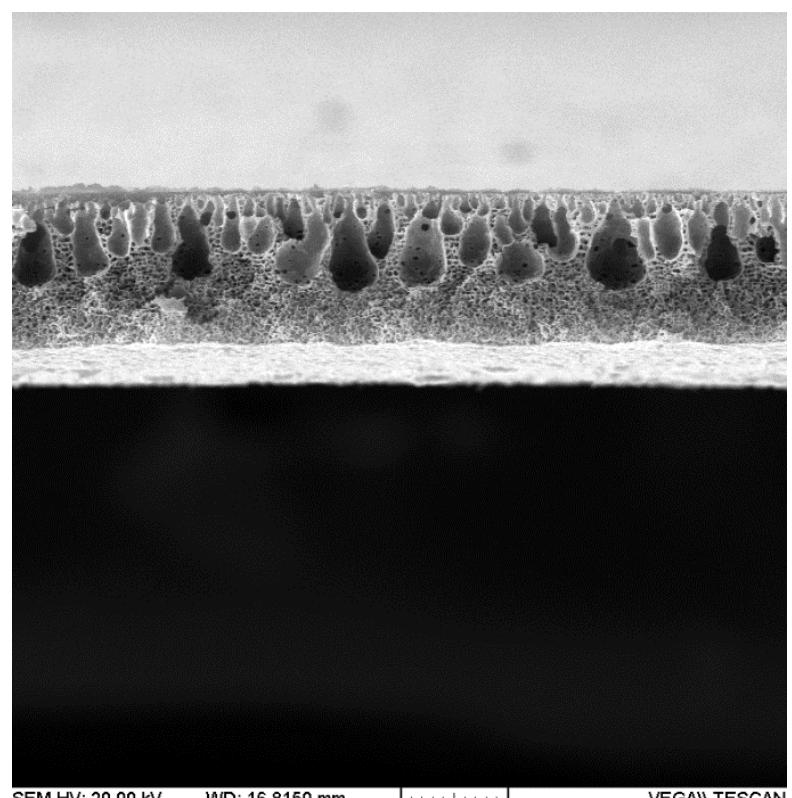

SEM MAG: $1.50 \mathrm{kx}$ Det: SE

$\frac{\mid+11}{20 \mu \mathrm{m}}$

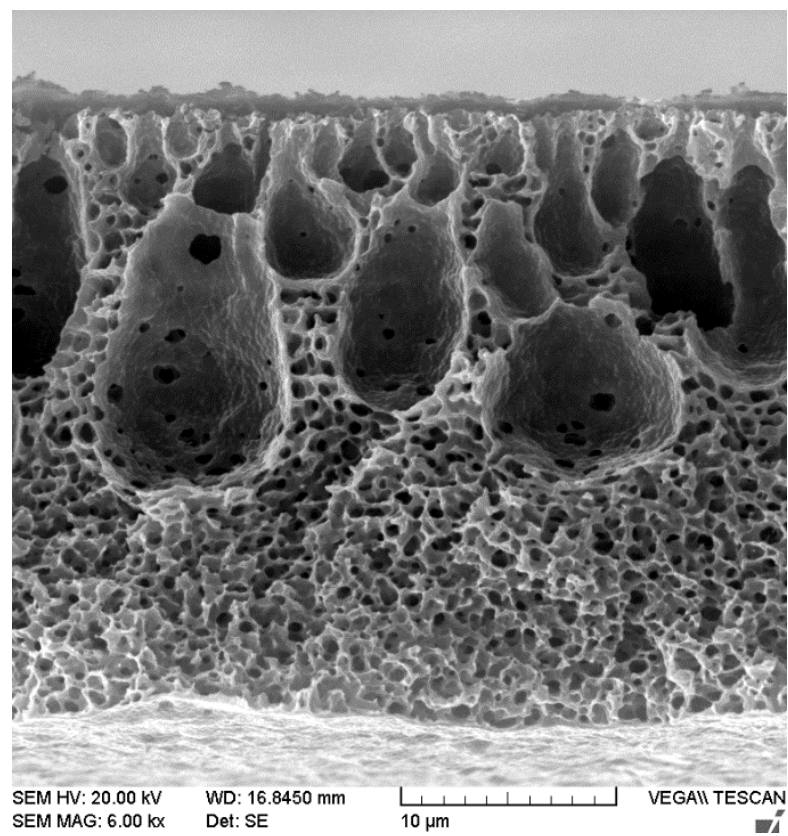

$2.0 \mathrm{wt} \%$ 


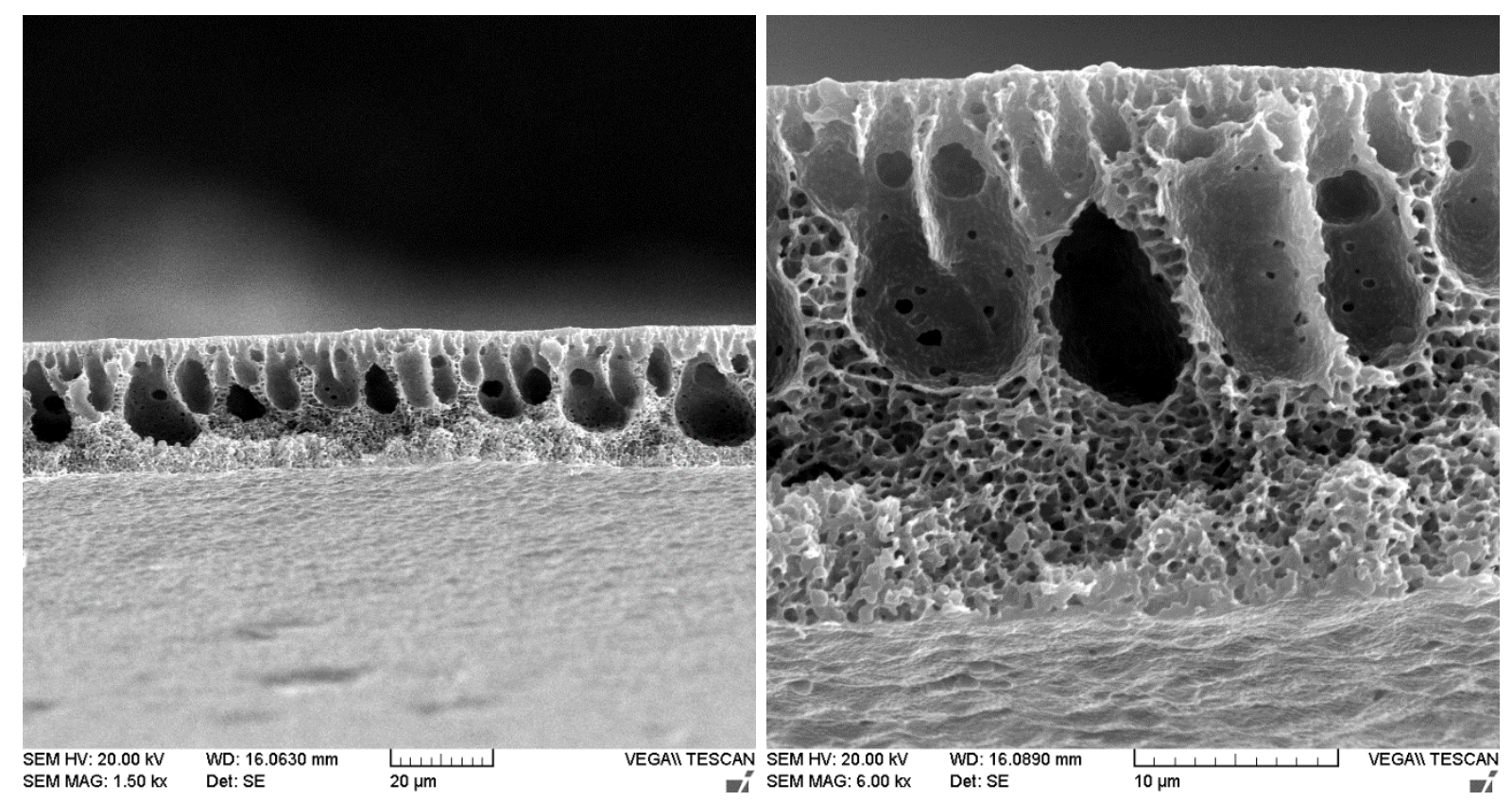

\section{$5.0 \mathrm{wt} \%$}

Fig. 4. Cross-sectional SEM images of the PVDF membranes with different concentrations of SAPO-34.

By more searching of the cross-sectional images of the prepared nanocomposite during the image capturing, only the presence of SAPO-34 zeolite particles was observed in the membrane containing $5 \mathrm{wt} \%$ of SAPO-34, as presented in Fig. 5.

Due to its hydrophilic nature, SAPO-34 particles may migrate spontaneously to the membrane/water interface during phase inversion and thus a hydrophilic surface can be attained [32]. However, these particles were not observed in other membranes due to the low concentration of SAPO-34 as well as its proper dispersion in the polymer matrix.

To confirm the presence and good dispersion of the SAPO-34 in matrix of the membrane, the EDX analysis was utilized. The EDX spectrum of $0.5 \mathrm{wt} \%$ SAPO-34/PVDF membrane is presented in Fig. 6a. The presence of silicon $(\mathrm{Si})$ and aluminum (Al) elements in the mixed matrix membrane is established by this analysis. In addition, Fig. 6b shows the EDX mapping of Si element, which reveals the homogeneous dispersion of SAPO-34 within the membrane 
matrix. The red points in this map are Si element of SAPO-34 zeolite in the modified membrane.

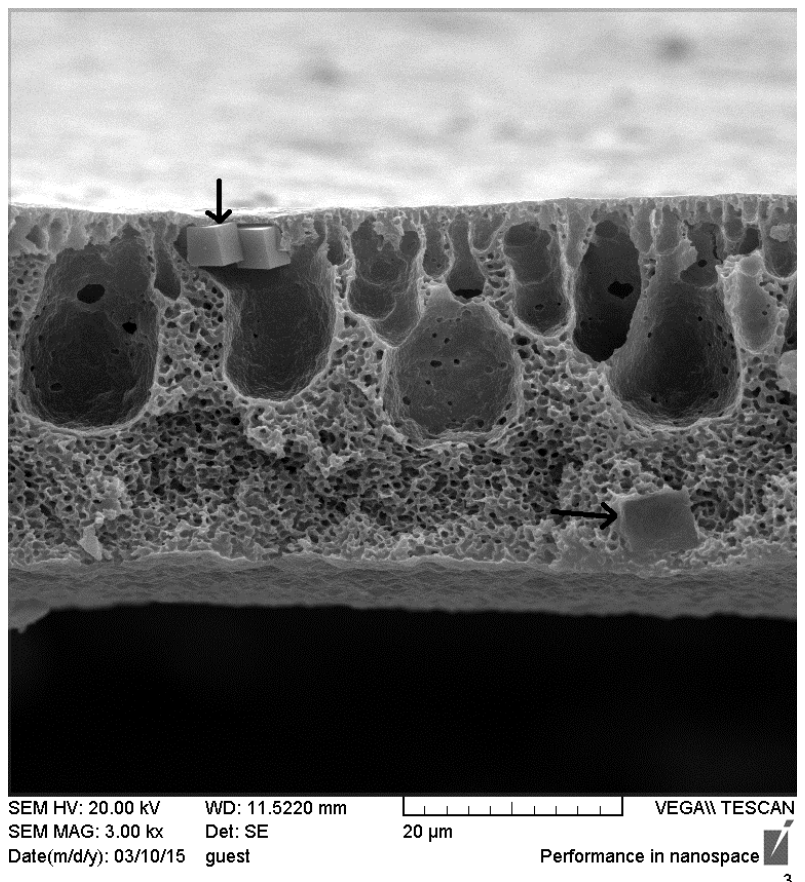

Fig. 5. Observation of SAPO-34 zeolite in the matrix of $5 \mathrm{wt} \%$ membrane.

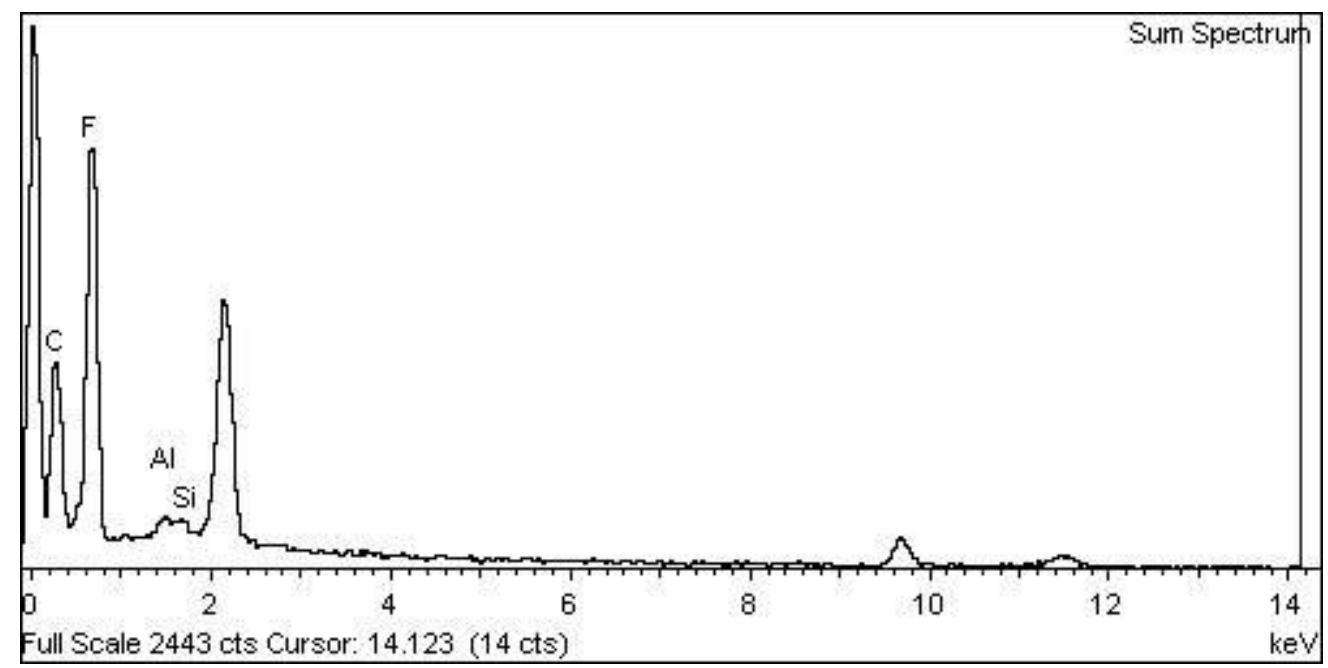

(a) 


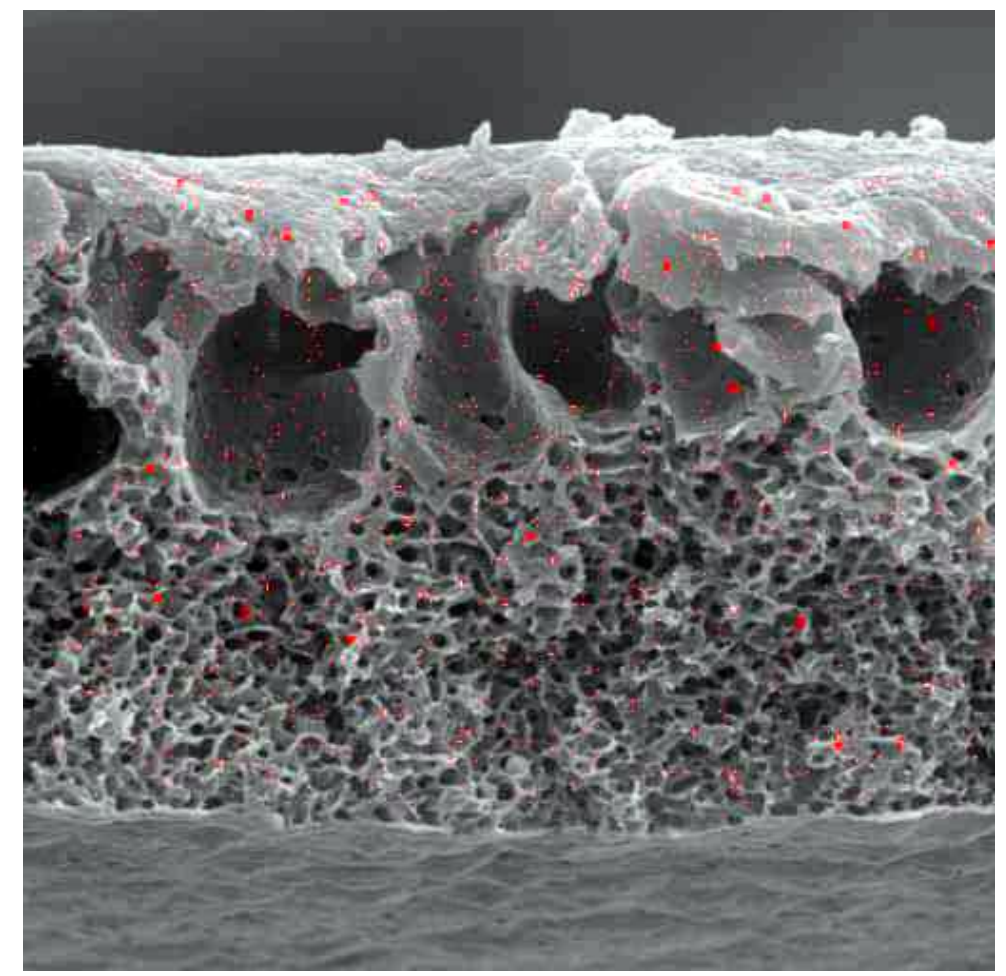

(b)

Fig. 6. (a) EDX spectrum and (b) EDX mapping of Si element of $0.5 \mathrm{wt} \%$ SAPO-34/PVDF blended membrane.

The surface hydrophilicity of the bare and mixed matrix PVDF membranes was investigated by water contact angle analysis. In general, a low contact angle presents a more hydrophilic surface. The results of contact angle measurements for the membranes modified with different contents of SAPO-34 are given in Fig. 7. The contact angle of the bare PVDF membrane (without SAPO-34) decreases gradually by increasing SAPO-34 loading and the minimum value is observed for membrane containing $5.0 \mathrm{wt} \%$ SAPO-34 $\left(75.2^{\circ}\right)$ with a reduction around $15 \%$. Zeolites are microporous/nanoporous three-dimensional crystalline solids with well-defined structures, which contain silicon, aluminum, and oxygen in their regular framework [4]. Decreased contact angle of the blended membranes may be due to their increased hydrophilicity. These results suggest that SAPO-34 zeolite particles $(\mathrm{Si} / \mathrm{Al}=2.5)$ have desirable hydrophilicity and improve the hydrophilicity of the modified 
PVDF membranes. The higher hydrophilicity of the blended membranes can also be related to the "negative charged centers" on the surface of zeolite containing membranes [26].

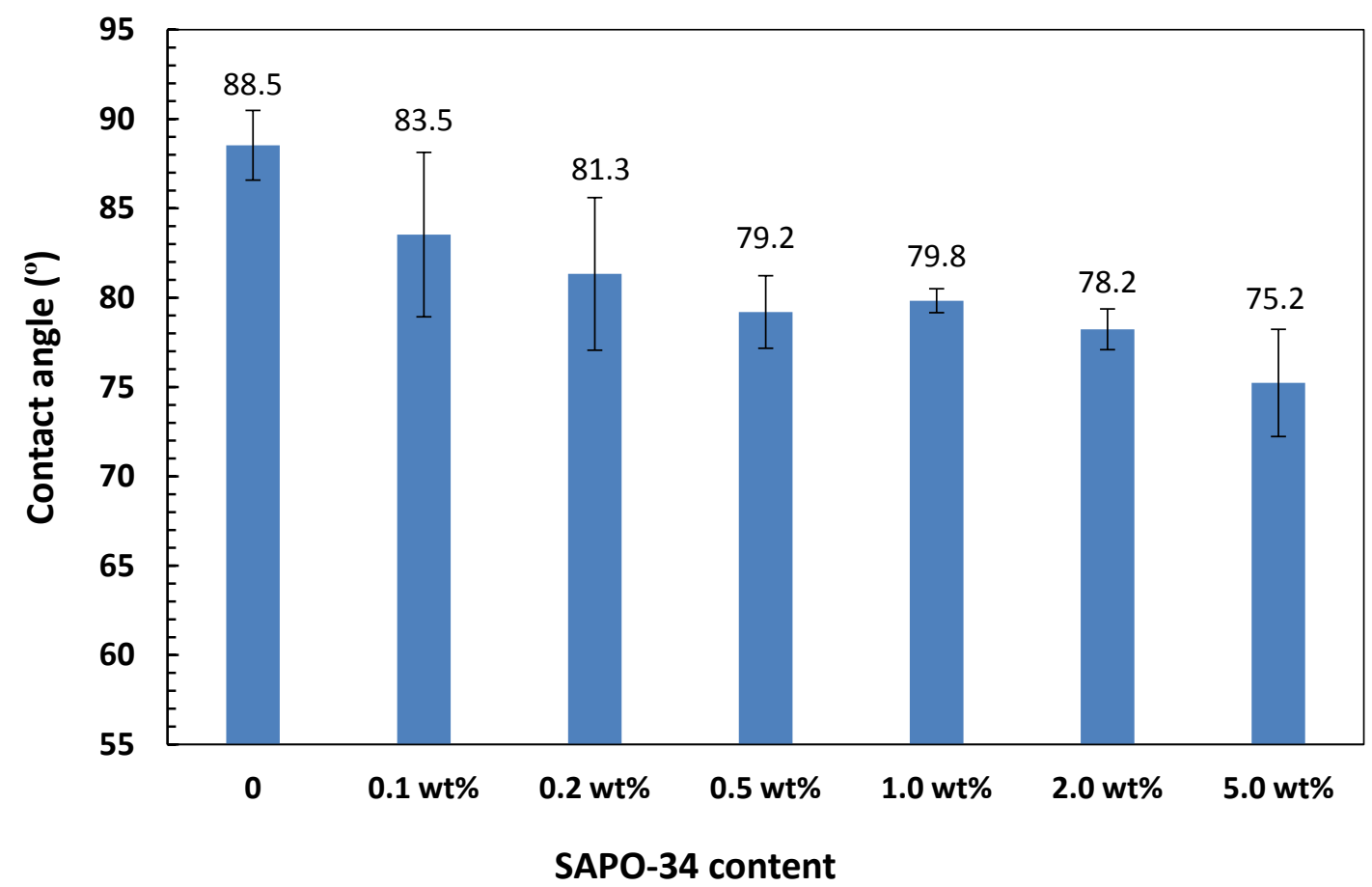

Fig. 7. Water contact angle of the prepared PVDF membranes with different concentrations of SAPO-34.

\subsubsection{Effect of SAPO-34 on the permeability, porosity and BSA retention of membranes}

Fig. 8 shows the pure water flux before and after BSA filtration and BSA flux of the prepared PVDF membranes containing different contents of SAPO-34. As shown in this Figure, all of the nanocomposite membranes have higher water and protein flux compared to the bare PVDF. Maximum water flux $\left(74.8 \mathrm{~kg} / \mathrm{m}^{2} \mathrm{~h}\right)$ was obtained for membrane modified with 1.0 wt $\%$ SAPO-34 with an increase around $60 \%$ compared to the unmodified membrane. Comparing trend of pure water flux and water contact angle shows that increase in the water flux of the embedded membranes has the similar trend of hydrophilicity improvement. It has been well approved that membrane hydrophilicity increasing leads to the water permeability 
increase by adsorbing molecules of water within the membrane matrix and promoting their permeation through the membrane. Also, the nanoporous SAPO-34 was characterized by the hydrophilic framework and high pore volume, indicating the high water adsorption and rapid water diffusion inside the pores, and thus the high water flux [26]. Nevertheless, higher contents of SAPO-34 lead to decrease in water flux. This manner can be associated to tendency of inorganic materials to aggregation [33]. Zeolite particles due to the hydroxyl groups on its surface and their high specific surface area are susceptible to aggregation and formation of large size clusters which might block the membrane pores and decline the water permeability [34].

The flux decay at high zeolite concentrations was seen as a decrease in the overall porosity of the membranes (Table 1). As shown in Table 1, the porosity of the membranes blended with low amount of SAPO-34 was slightly higher than that of the unfilled PVDF membrane. This behavior can be related to the hydrophilic nature of the nanoporous zeolite particles which leads to the fast exchange of solvent of polymer and bath non-solvent during the phase inversion process and forms membranes with high porosity [35]. The same behavior have been reported by Wang et al. [36], Zinadini et al. [33] and Safarpour et al. [8] for blended membranes. However, the porosity of the membranes containing higher contents of SAPO-34 was decreased again may be due to viscosity increment and the pore blocking effect of excess amount of this additive. At higher SAPO-34 concentrations, the viscosity of the casting solution increased and reduced the overall porosity of the respective membranes and consequently, led to a decrease in the permeability [33]. The results of BSA rejection by SAPO-34/PVDF membranes are also given in Table 1. As can be seen, all of the prepared PVDF membranes rejected more than $97 \%$ of the BSA protein confirming that flux enhancements of the modified membranes were not due to cracks and defects in the membranes. The BSA rejection was slightly increased in the blended membranes compared 
to the unmodified PVDF which may be due to the higher retention of hydrophobic BSA protein by more hydrophilic surface.

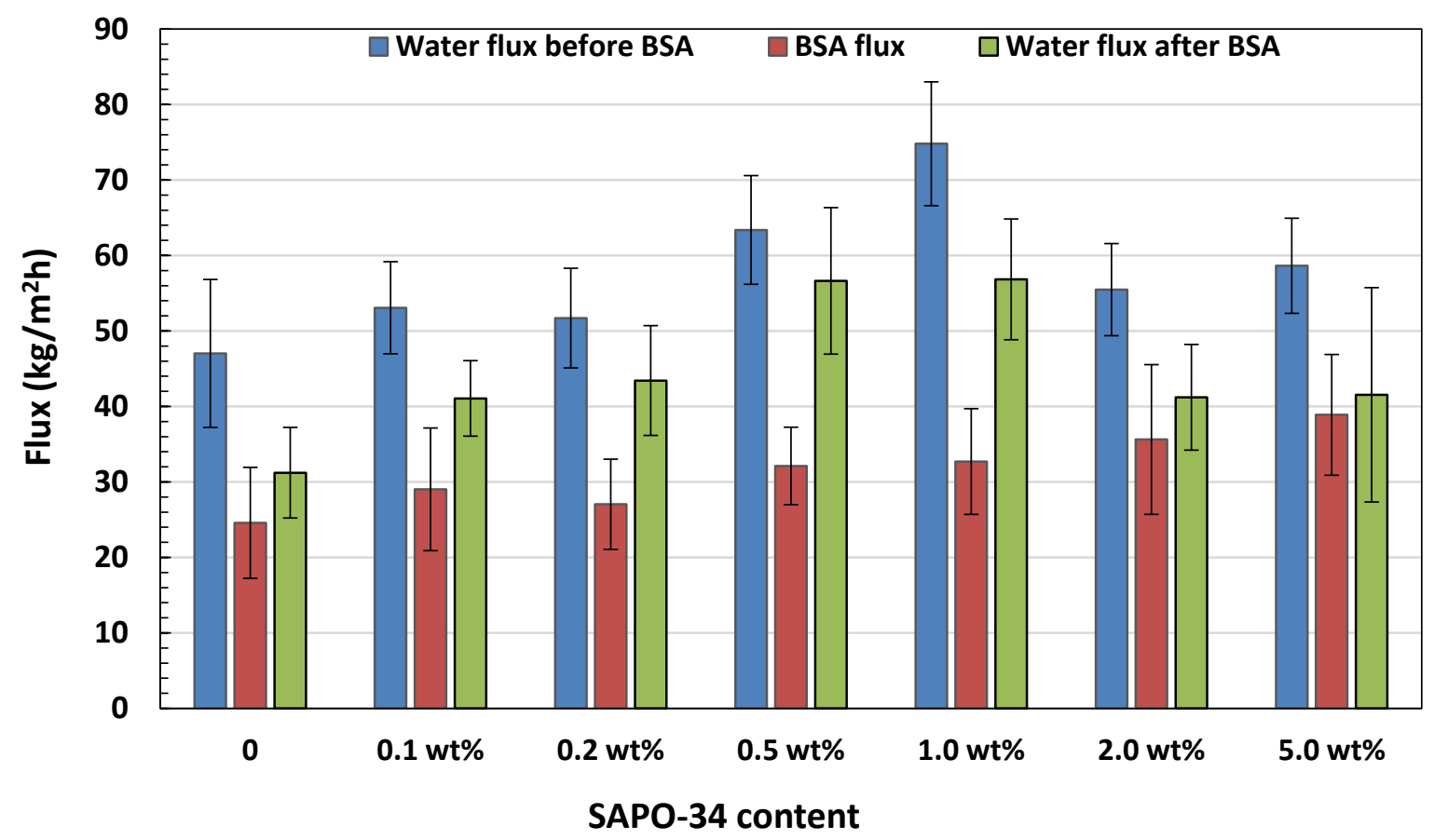

Fig. 8. Water flux (before and after BSA filtration) and BSA flux of the prepared PVDF membranes with different concentrations of SAPO-34 (after 90 min at $0.3 \mathrm{MPa}$ ).

Table 1. Overall porosity and BSA rejection of the prepared PVDF membranes.

\begin{tabular}{cccccccc}
$\begin{array}{c}\text { SAPO-34 content } \\
(\mathbf{w t} \%) \text { in membrane } \\
\text { matrix }\end{array}$ & 0 & 0.1 & 0.2 & 0.5 & 1.0 & 2.0 & 5.0 \\
\hline Overall porosity (\%) & $67.1 \pm 0.4$ & $67.6 \pm 0.2$ & $71.7 \pm 0.1$ & $70.8 \pm 0.6$ & $68.3 \pm 0.1$ & $66.9 \pm 0.2$ & $66.1 \pm 0.3$ \\
\hline BSA rejection (\%) & $97.4 \pm 1.0$ & $98.9 \pm 0.2$ & $99.6 \pm 0.4$ & $99.5 \pm 0.3$ & $98.8 \pm 0.6$ & $98.1 \pm 0.4$ & $99.4 \pm 0.1$ \\
\hline
\end{tabular}

Fig. 8 also shows the decline in the permeability of the PVDF membranes during and after BSA filtration. The flux decline is much serious for the unfilled PVDF membrane that represents its high fouling tendency compared to the modified membranes. 


\subsubsection{Effect of SAPO-34 on the antifouling performance of membranes}

To compare the fouling of the prepared membranes, the FRR (\%) parameter was calculated using Eq. (3) and exhibited in Fig. 9. This figure shows that the FRR (\%) of all of the modified membranes is higher than that of the bare PVDF membrane. The flux recovery ratio of the unmodified membrane was $66.4 \%$ after 90 min while it reached to $89.4 \%$ using 0.5 wt $\%$ SAPO-35 blended membrane, confirming the superior antifouling ability of this membrane. In fact, the fouling phenomena of a membrane is quite complex. The better antifouling performance of the blended membranes can be attributed to their increased hydrophilicity, the improved smoothness of the membrane surface and a more surface negative zeta potential. The hydrophilicity of membrane surface controls its adsorption properties and a more hydrophilic surface can reduce the attachment of hydrophobic fouling agents and membrane fouling [37]. The incorporation of SAPO-34 particles enhanced the hydrophilicity of the PVDF membrane surface and pore walls that made more difficult the adsorption of foulants by the blended membranes compared with the unmodified PVDF. In addition, the improvement of hydrophilicity of the membrane can reduce the rate of the interfacial resistance, and the adsorbed foulants on the inorganic/PVDF nanocomposite membrane can be more readily removed by shear force than those on the bare PVDF membrane [38]. As mentioned by other researchers [1, 8], the increased fouling at higher concentration of inorganic additives can be related to the increasing of roughness of membrane surface. The roughness increase is due to the accumulation of excess amount of additive (SAPO-34) on the membrane surface which leads to penetration/adhesion of foulants in the valleys/peaks of the rough surface and decreases the flux recovery ratio.

So, the membranes modified with low amount of SAPO-34 particles displayed better antifouling ability. This trend was in good agreement with the increase of pure water flux. 


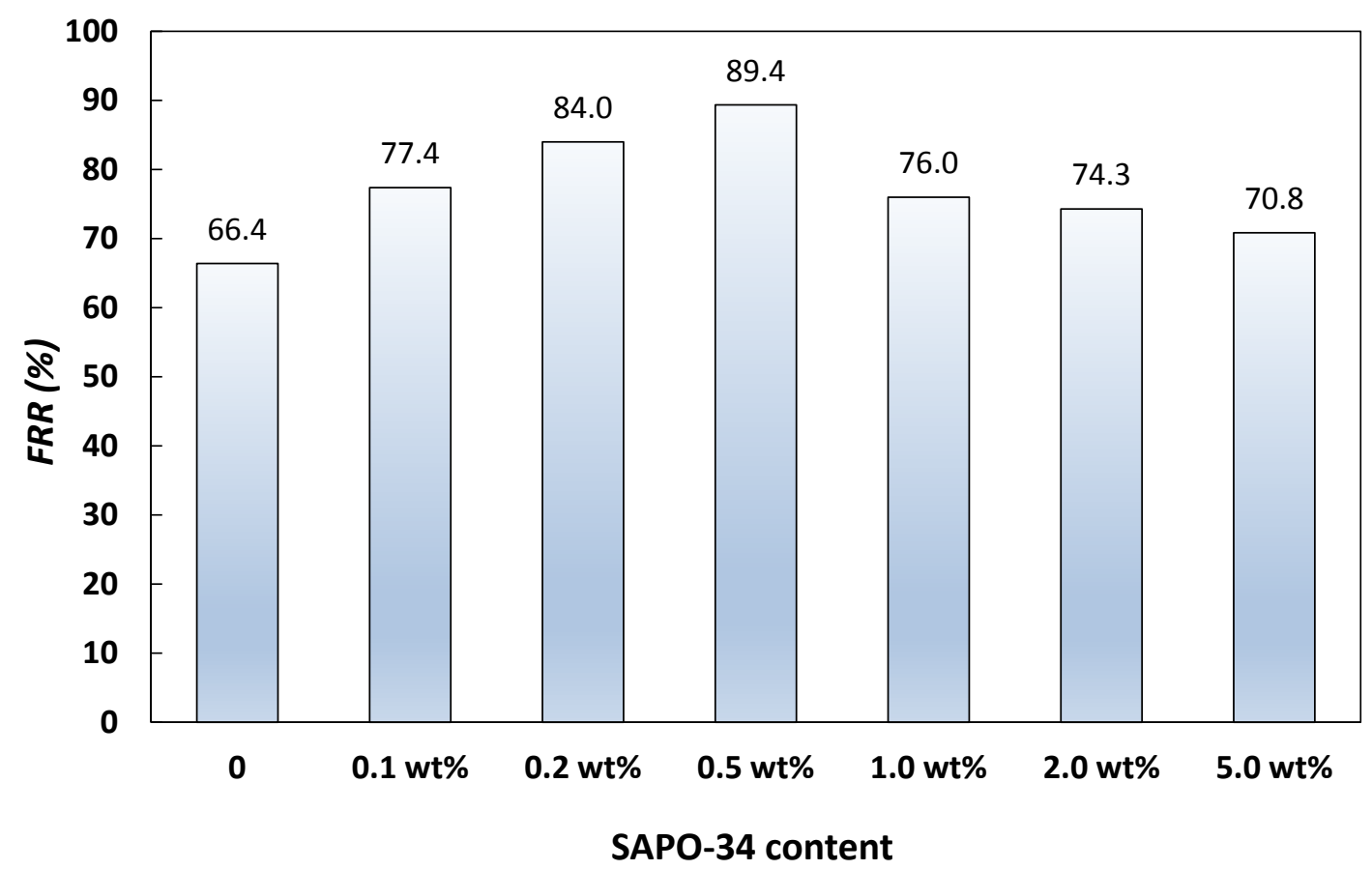

Fig. 9. Flux recovery ratio (FRR (\%)) of the prepared PVDF membranes with different concentrations of SAPO-34.

Moreover, the fouling resistance parameters of the prepared membranes are shown in Fig. 10. As shown in this figure, the $R_{i r}$ of the unmodified PVDF membrane is the main part of its total fouling. The irreversible fouling is caused by rigid adsorption of fouling agents on the surface or entrapment of them in the pores; while, reversible fouling is due to reversible foulants adsorption and can be removed by simple hydraulic cleaning [39]. In the PVDF membranes blended with SAPO-34, the irreversible part of the total fouling $\left(R_{i r}\right)$ decreased remarkably and the lowest $R_{i r}$ value was observed for $1.0 \mathrm{wt} \%$ SAPO-34/PVDF membrane indicating its improved antifouling ability. 


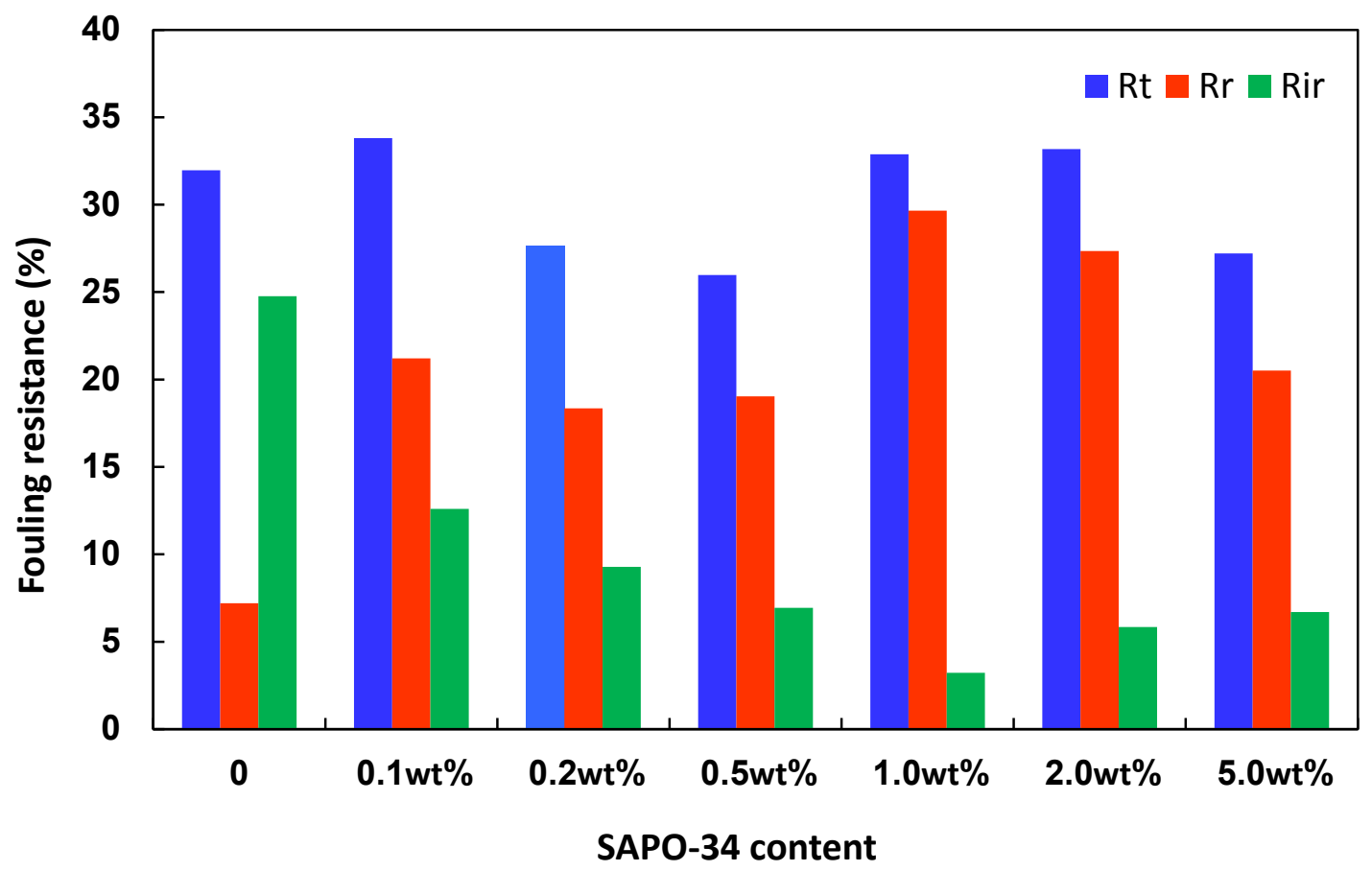

Fig. 10. Fouling resistance ratio of the PVDF membranes with different concentrations of SAPO-34.

\subsection{Comparison with other blended membranes}

There are several inorganic materials blended to the polymeric membranes in the literature. A number of these studies are presented and compared in the Table 2. Zeolites such as SAPO34 are one of the permissible and economic materials used to improve the performance of the polymeric membranes. However, to the best of our knowledge, there was not any study on the modifying PVDF membranes using SAPO-34. As shown in the Table 2, the results of the present study introduced the SAPO-34 as an efficient inorganic material to modify PVDF membranes. 
Table 2. Comparison of various blended membranes modified with inorganic materials (pressures may be different).

\begin{tabular}{cccccc}
\hline $\begin{array}{c}\text { Membranes (optimum content } \\
\text { of additive) }\end{array}$ & $\begin{array}{c}\text { Water flux } \\
\left(\mathbf{k g} / \mathbf{m}^{\mathbf{2}} \mathbf{h}\right)\end{array}$ & $\begin{array}{c}\text { BSA rejection } \\
\mathbf{( \% )}\end{array}$ & $\begin{array}{c}\text { Contact } \\
\text { angle } \mathbf{(})\end{array}$ & $\begin{array}{c}\text { Flux recovery } \\
\text { ratio }(\boldsymbol{\%})\end{array}$ & Ref. \\
\hline $\mathrm{PVDF} / \mathrm{AgNaY}(0.8 \mathrm{wt} \%)$ & $\sim 670$ & 92 & 82 & $\sim 70$ & {$[4]$} \\
\hline $\mathrm{PSf} / \mathrm{SAPO}-44(15.0 \mathrm{wt} \%)$ & 36 & - & 66 & $\sim 80$ & {$[40]$} \\
\hline $\mathrm{PVDF} / \mathrm{ZnO}(0.005 \mathrm{wt} \%)$ & $\sim 430$ & $\sim 30$ & $\sim 80$ & $\sim 50$ & {$[41]$} \\
\hline $\mathrm{PVDF} / \mathrm{Al}_{2} \mathrm{O}_{3}(2.0 \mathrm{wt} \%)$ & $\sim 150$ & 96 & 57 & - & {$[9]$} \\
\hline $\mathrm{PVDF} / \mathrm{SiO}_{2}(3.0 \mathrm{wt} \%)$ & $\sim 250$ & 90 & 53 & - & {$[38]$} \\
\hline $\mathrm{PVDF} / \mathrm{TiO}_{2}(5.0 \mathrm{wt} \%)$ & 266 & 90 & 35 & - & {$[12]$} \\
\hline $\mathrm{PVDF} / \mathrm{MWCNTs}(1.0 \mathrm{wt} \%)$ & 620 & 89 & 53 & 114 & {$[42]$} \\
\hline $\mathrm{PVDF} / \mathrm{GO}(1.0 \mathrm{wt} \%)$ & 505 & 87.0 & 68 & 74 & {$[42]$} \\
\hline $\mathrm{PVDF} / \mathrm{GO} / \mathrm{OMWCNTs}(1 \mathrm{wt} \%)$ & $\sim 406$ & - & 52 & 98 & {$[43]$} \\
\hline $\mathrm{PSf} / \mathrm{SiO}{ }_{2}-\mathrm{GO}(0.3 \mathrm{wt} \%)$ & $\sim 370$ & $>98$ & $\sim 62$ & 72 & {$[39]$} \\
\hline $\mathrm{PVDF} / \mathrm{GO}(0.2 \mathrm{wt} \%)$ & 457 & 91 & 61 & 96 & {$[36]$} \\
\hline $\mathrm{PVDF} / \mathrm{GO}(2.0 \mathrm{wt} \%)$ & 25 & - & 64 & $\sim 80$ & {$[44]$} \\
\hline $\mathrm{PVDF} / \mathrm{rGO} / \mathrm{TiO}{ }_{2}(0.05 \mathrm{wt} \%)$ & 221 & 99 & 69 & 95 & {$[1]$} \\
\hline $\mathrm{PVDF} / \mathrm{SAPO}-34(0.5-1.0 \mathrm{wt} \%)$ & $\sim 75$ & $>98$ & 79 & $>89$ & This \\
\hline
\end{tabular}

\section{Conclusion}

In the present study, nanoporous SAPO-34 zeolite was incorporated into the polymer matrix of PVDF membranes with the aim of improving their hydrophilicity, permeability and antifouling ability. The SEM analysis showed the asymmetric structure of the prepared membranes without any significant change in the morphology of the modified membranes. The result of water contact angle measurement confirmed that the introduction of SAPO-34 particles improved the surface hydrophilicity of the blended membranes, and therefore increased the pure water flux and the antifouling performance of the PVDF membranes. The membrane containing $0.5 \mathrm{wt} \%$ SAPO-34 showed the best antifouling performance with a FRR value of $89.35 \%$. All of the membranes had BSA retention value of above $97 \%$. The results of this study revealed that SAPO-34 can be an excellent inorganic additive to polymeric membranes. Consequently, it can be an encouraging material for new applications in the membrane filed. 


\section{Acknowledgments}

The authors gratefully thank the Kharazmi University, Tehran, Iran for the financial support of this study. Also, the authors thankfully acknowledge the financial support by the Iran National Science Foundation (INSF) (Grant no. 91055010). 


\section{References}

[1] R. Kumar, A.F. Ismail, Fouling control on microfiltration/ultrafiltration membranes: Effects of morphology, hydrophilicity, and charge, J. Appl. Polym. Sci. 2015, DOI: 10.1002/APP.42042.

[1] M. Safarpour, A.R. Khataee, V. Vatanpour, Effect of reduced graphene oxide/TiO ${ }_{2}$ nanocomposite with different molar ratios on the performance of PVDF ultrafiltration membranes, Sep. Purif. Technol., 140 (2015) 32-42.

[2] J. Zhang, Z. Xu, W. Mai, C. Min, B. Zhou, M. Shan, Y. Li, C. Yang, Z. Wang, X. Qian, Improved hydrophilicity, permeability, antifouling and mechanical performance of PVDF composite ultrafiltration membranes tailored by oxidized low-dimensional carbon nanomaterials, J. Mater. Chem. A, 1 (2013) 3101-3111.

[3] K. Jian, P.N. Pintauro, R. Ponangi, Separation of dilute organic/water mixtures with asymmetric poly(vinylidene fluoride) membranes, J. Membr. Sci., 117 (1996) 117-133.

[4] C. Liao, P. Yu, J. Zhao, L. Wang, Y. Luo, Preparation and characterization of NaY/PVDF hybrid ultrafiltration membranes containing silver ions as antibacterial materials, Desalination, 272 (2011) 59-65.

[5] Y.-H. Zhao, B.-K. Zhu, L. Kong, Y.-Y. Xu, Improving hydrophilicity and protein resistance of poly (vinylidene fluoride) membranes by blending with amphiphilic hyperbranched-star polymer, Langmuir, 23 (2007) 5779-5786.

[6] Y. Chang, Y.-J. Shih, R.-C. Ruaan, A. Higuchi, W.-Y. Chen, J.-Y. Lai, Preparation of poly(vinylidene fluoride) microfiltration membrane with uniform surface-copolymerized poly(ethylene glycol) methacrylate and improvement of blood compatibility, J. Membr. Sci., 309 (2008) 165-174. 
[7] Y. Chen, Q. Deng, J. Xiao, H. Nie, L. Wu, W. Zhou, B. Huang, Controlled grafting from poly(vinylidene fluoride) microfiltration membranes via reverse atom transfer radical polymerization and antifouling properties, Polymer, 48 (2007) 7604-7613.

[8] M. Safarpour, A.R. Khataee, V. Vatanpour, Preparation of a novel polyvinylidene fluoride (PVDF) ultrafiltration membrane modified with reduced graphene oxide/titanium dioxide $\left(\mathrm{TiO}_{2}\right)$ nanocomposite with enhanced hydrophilicity and antifouling properties, Ind. Eng. Chem. Res., 53 (2014) 13370-13382.

[9] L. Yan, Y.S. Li, C.B. Xiang, S. Xianda, Effect of nano-sized $\mathrm{Al}_{2} \mathrm{O}_{3}$-particle addition on PVDF ultrafiltration membrane performance, J. Membr. Sci., 276 (2006) 162-167.

[10] A. Cui, Z. Liu, C. Xiao, Y. Zhang, Effect of micro-sized $\mathrm{SiO}_{2}$-particle on the performance of PVDF blend membranes via TIPS, J. Membr. Sci., 360 (2010) 259-264.

[11] X. Cao, J. Ma, X. Shi, Z. Ren, Effect of $\mathrm{TiO}_{2}$ nanoparticle size on the performance of PVDF membrane, Appl. Surf. Sci., 253 (2006) 2003-2010.

[12] Y. Wei, H.-Q. Chu, B.-Z. Dong, X. Li, S.-J. Xia, Z.-M. Qiang, Effect of $\mathrm{TiO}_{2}$ nanowire addition on PVDF ultrafiltration membrane performance, Desalination, 272 (2011) 90-97.

[13] M.A. Aroon, A.F. Ismail, T. Matsuura, M.M. Montazer-Rahmati, Performance studies of mixed matrix membranes for gas separation: A review, Sep. Purif. Technol., 75 (2010) 229242.

[14] M. Rezakazemi, A. Ebadi Amooghin, M.M. Montazer-Rahmati, A.F. Ismail, T. Matsuura, State-of-the-art membrane based $\mathrm{CO}_{2}$ separation using mixed matrix membranes (MMMs): An overview on current status and future directions, Prog. Polym. Sci., 39 (2014) 817-861.

[15] R. Shah, J. D. Gale, M. C. Payne, Comparing the acidities of zeolites and SAPOs from first principles, Chem. Commun., (1997) 131-132. 
[16] L.Y.J. T.-S. Chung, Y. Li, S. Kulprathipanj, Mixed matrix membranes (MMMs) comprising organic polymers with dispersed inorganic fillers for gas separation, Prog. Polym. Sci., 32 (2007) 483-507.

[17] S. Li, Z. Zong, S.J. Zhou, Y. Huang, Z. Song, X. Feng, R. Zhou, H.S. Meyer, M. Yu, M.A. Carreon, SAPO-34 Membranes for $\mathrm{N}_{2} / \mathrm{CH}_{4}$ separation: Preparation, characterization, separation performance and economic evaluation, J. Membr. Sci., 487 (2015) 141-151.

[18] S. Li, J.L. Falconer, R.D. Noble, SAPO-34 membranes for $\mathrm{CO}_{2} / \mathrm{CH}_{4}$ separation, J. Membr. Sci., 241 (2004) 121-135.

[19] S. Li, G. Alvarado, R.D. Noble, J.L. Falconer, Effects of impurities on $\mathrm{CO}_{2} / \mathrm{CH}_{4}$ separations through SAPO-34 membranes, J. Membr. Sci., 251 (2005) 59-66.

[20] M.U.M. Junaidi, C.P. Leo, A.L. Ahmad, N.A. Ahmad, Fluorocarbon functionalized SAPO-34 zeolite incorporated in asymmetric mixed matrix membranes for carbon dioxide separation in wet gases, Microporous and Mesoporous Materials, 206 (2015) 23-33.

[21] H. Rabiee, S. Meshkat Alsadat, M. Soltanieh, S.A. Mousavi, A. Ghadimi, Gas permeation and sorption properties of poly(amide-12-b-ethyleneoxide)(Pebax 1074)/SAPO-34 mixed matrix membrane for $\mathrm{CO}_{2} / \mathrm{CH}_{4}$ and $\mathrm{CO}_{2} / \mathrm{N}_{2}$ separation, J. Ind. Eng. Chem., 27 (2015) 223-239.

[22] Y.C. Hudiono, T.K. Carlisle, A.L. LaFrate, D.L. Gin, R.D. Noble, Novel mixed matrix membranes based on polymerizable room-temperature ionic liquids and SAPO-34 particles to improve $\mathrm{CO}_{2}$ separation, J. Membr. Sci., 370 (2011) 141-148.

[23] M. Peydayesh, S. Asarehpour, T. Mohammadi, O. Bakhtiari, Preparation and characterization of SAPO-34 - Matrimid® 5218 mixed matrix membranes for $\mathrm{CO}_{2} / \mathrm{CH}_{4}$ separation, Chem. Eng. Res. Des., 91 (2013) 1335-1342. 
[24] E.W. Ping, R. Zhou, H.H. Funke, J.L. Falconer, R.D. Noble, Seeded-gel synthesis of SAPO-34 single channel and monolith membranes, for $\mathrm{CO}_{2} / \mathrm{CH}_{4}$ separations, J. Membr. Sci., 415-416 (2012) 770-775.

[25] M.U.M. Junaidi, C.P. Leo, S.N.M. Kamal, A.L. Ahmad, Fouling mitigation in humic acid ultrafiltration using polysulfone/SAPO-34 mixed matrix membrane, Water Sci. Technol., 67 (2013) 2102-2109.

[26] T.-Y. Liu, Z.-H. Liu, R.-X. Zhang, Y. Wang, B.V.d. Bruggen, X.-L. Wang, Fabrication of a thin film nanocomposite hollow fiber nanofiltration membrane for wastewater treatment, J. Membr. Sci., 488 (2015) 92-102.

[27] J.-F. Li, Z.-L. Xu, H. Yang, L.-Y. Yu, M. Liu, Effect of $\mathrm{TiO}_{2}$ nanoparticles on the surface morphology and performance of microporous PES membrane, Appl. Surf. Sci., 255 (2009) 4725-4732.

[28] M. Salmasi, S. Fatemi, S.J. Hashemi, MTO reaction over SAPO-34 catalysts synthesized by combination of TEAOH and morpholine templates and different silica sources, Scientia Iranica, 19 (2012) 1632-1637.

[29] T. Sano, H. Yanagishita, Y. Kiyozumi, F. Mizukami, K. Haraya, Separation of ethanol/water mixture by silicalite membrane on pervaporation, J. Membr. Sci., 95 (1994) 221-228.

[30] D.F. Mohshim, Z.M. Hilmi Mukhtar, The effect of incorporating ionic liquid into polyethersulfone-SAPO34 based mixed matrix membrane on $\mathrm{CO}_{2}$ gas separation performance, Sep. Purif. Technol., 135 (2014) 252-258.

[31] P. Sukitpaneenit, T.-S. Chung, Molecular elucidation of morphology and mechanical properties of PVDF hollow fiber membranes from aspects of phase inversion, crystallization and rheology, J. Membr. Sci., 340 (2009) 192-205. 
[32] Y.P. Tang, J.X. Chan, T.S. Chung, M. Weber, C. Staudt, C. Maletzko, Simultaneously covalent and ionic bridging towards antifouling of GO-imbedded nanocomposite hollow fiber membranes, J. Mater. Chem. A, 3 (2015) 10573-10584.

[33] S. Zinadini, A.A. Zinatizadeh, M. Rahimi, V. Vatanpour, H. Zangeneh, Preparation of a novel antifouling mixed matrix PES membrane by embedding graphene oxide nanoplates, J. Membr. Sci., 453 (2014) 292-301.

[34] A. Sotto, A. Boromand, R. Zhang, P. Luis, J.M. Arsuaga, J. Kim, B. Van der Bruggen, Effect of nanoparticle aggregation at low concentrations of $\mathrm{TiO}_{2}$ on the hydrophilicity, morphology, and fouling resistance of PES-TiO 2 membranes, J. Colloid Interf. Sci., 363 (2011) 540-550.

[35] V. Vatanpour, S.S. Madaeni, R. Moradian, S. Zinadini, B. Astinchap, Fabrication and characterization of novel antifouling nanofiltration membrane prepared from oxidized multiwalled carbon nanotube/polyethersulfone nanocomposite, J. Membr. Sci., 375 (2011) 284-294.

[36] Z. Wang, H. Yu, J. Xia, F. Zhang, F. Li, Y. Xia, Y. Li, Novel GO-blended PVDF ultrafiltration membranes, Desalination, 299 (2012) 50-54.

[37] V. Vatanpour, S.S. Madaeni, R. Moradian, S. Zinadini, B. Astinchap, Novel antibifouling nanofiltration polyethersulfone membrane fabricated from embedding $\mathrm{TiO}_{2}$ coated multiwalled carbon nanotubes, Sep. Purif. Technol., 90 (2012) 69-82.

[38] L.-Y. Yu, Z.-L. Xu, H.-M. Shen, H. Yang, Preparation and characterization of PVDF$\mathrm{SiO}_{2}$ composite hollow fiber UF membrane by sol-gel method, J. Membr. Sci., 337 (2009) 257-265.

[39] H. Wu, B. Tang, P. Wu, Development of novel $\mathrm{SiO}_{2}-\mathrm{GO}$ nanohybrid/polysulfone membrane with enhanced performance, J. Membr. Sci., 451 (2014) 94-102. 
[40] C.P. Leo, N.H. Ahmad Kamil, M.U.M. Junaidi, S.N.M. Kamal, A.L. Ahmad, The potential of SAPO-44 zeolite filler in fouling mitigation of polysulfone ultrafiltration membrane, Sep. Purif. Technol., 103 (2013) 84-91.

[41] J. Hong, Y. He, Effects of nano sized zinc oxide on the performance of PVDF microfiltration membranes, Desalination, 302 (2012) 71-79.

[42] Y. Zhao, Z. Xu, M. Shan, C. Min, B. Zhou, Y. Li, B. Li, L. Liu, X. Qian, Effect of graphite oxide and multi-walled carbon nanotubes on the microstructure and performance of PVDF membranes, Sep. Purif. Technol., 103 (2013) 78-83.

[43] J. Zhang, Z. Xu, M. Shan, B. Zhou, Y. Li, B. Li, J. Niu, X. Qian, Synergetic effects of oxidized carbon nanotubes and graphene oxide on fouling control and anti-fouling mechanism of polyvinylidene fluoride ultrafiltration membranes, J. Membr. Sci., 448 (2013) $81-92$.

[44] C. Zhao, X. Xu, J. Chen, F. Yang, Effect of graphene oxide concentration on the morphologies and antifouling properties of PVDF ultrafiltration membranes, J. Environ. Chem. Eng., 1 (2013) 349-354. 


\section{Tables}

Table 1. Overall porosity and BSA rejection of the prepared PVDF membranes.

\begin{tabular}{cccccccc}
\hline $\begin{array}{c}\text { SAPO-34 content } \\
(\mathbf{w t} \%) \text { in membrane } \\
\text { matrix }\end{array}$ & 0 & 0.1 & 0.2 & 0.5 & 1.0 & 2.0 & 5.0 \\
\hline $\begin{array}{c}\text { Overall porosity (\%) } \\
6\end{array}$ & $67.1 \pm 0.4$ & $67.6 \pm 0.2$ & $71.7 \pm 0.1$ & $70.8 \pm 0.6$ & $68.3 \pm 0.1$ & $66.9 \pm 0.2$ & $66.1 \pm 0.3$ \\
\hline BSA rejection (\%) & $97.4 \pm 1.0$ & $98.9 \pm 0.2$ & $99.6 \pm 0.4$ & $99.5 \pm 0.3$ & $98.8 \pm 0.6$ & $98.1 \pm 0.4$ & $99.4 \pm 0.1$ \\
\hline
\end{tabular}


Table 2. Comparison of various blended membranes modified with inorganic materials (pressures may be different).

\begin{tabular}{cccccc}
\hline $\begin{array}{c}\text { Membranes (optimum content } \\
\text { of additive) }\end{array}$ & $\begin{array}{c}\text { Water flux } \\
\left(\mathbf{k g} / \mathbf{m}^{\mathbf{2}} \mathbf{h}\right)\end{array}$ & $\begin{array}{c}\text { BSA rejection } \\
\mathbf{( \% )}\end{array}$ & $\begin{array}{c}\text { Contact } \\
\text { angle }(\boldsymbol{(})\end{array}$ & $\begin{array}{c}\text { Flux recovery } \\
\text { ratio }(\boldsymbol{\%})\end{array}$ & Ref. \\
\hline $\mathrm{PVDF} / \mathrm{AgNaY}(0.8 \mathrm{wt} \%)$ & $\sim 670$ & 92 & 82 & $\sim 70$ & {$[4]$} \\
\hline $\mathrm{PSf} / \mathrm{SAPO}-44(15.0 \mathrm{wt} \%)$ & 36 & - & 66 & $\sim 80$ & {$[40]$} \\
\hline $\mathrm{PVDF} / \mathrm{ZnO}(0.005 \mathrm{wt} \%)$ & $\sim 430$ & $\sim 30$ & $\sim 80$ & $\sim 50$ & {$[41]$} \\
\hline $\mathrm{PVDF} / \mathrm{Al}_{2} \mathrm{O}_{3}(2.0 \mathrm{wt} \%)$ & $\sim 150$ & 96 & 57 & - & {$[9]$} \\
\hline $\mathrm{PVDF} / \mathrm{SiO}_{2}(3.0 \mathrm{wt} \%)$ & $\sim 250$ & 90 & 53 & - & {$[38]$} \\
\hline $\mathrm{PVDF} / \mathrm{TiO}_{2}(5.0 \mathrm{wt} \%)$ & 266 & 90 & 35 & - & {$[12]$} \\
\hline $\mathrm{PVDF} / \mathrm{MWCNTs}(1.0 \mathrm{wt} \%)$ & 620 & 89 & 53 & 114 & {$[42]$} \\
\hline $\mathrm{PVDF} / \mathrm{GO}(1.0 \mathrm{wt} \%)$ & 505 & 87.0 & 68 & 74 & {$[42]$} \\
\hline $\mathrm{PVDF} / \mathrm{GO} / \mathrm{OMWCNTs}(1 \mathrm{wt} \%)$ & $\sim 406$ & - & 52 & 98 & {$[43]$} \\
\hline $\mathrm{PSF} / \mathrm{SiO}{ }_{2}-\mathrm{GO}(0.3 \mathrm{wt} \%)$ & $\sim 370$ & $>98$ & $\sim 62$ & 72 & {$[39]$} \\
\hline $\mathrm{PVDF} / \mathrm{GO}(0.2 \mathrm{wt} \%)$ & 457 & 91 & 61 & 96 & {$[36]$} \\
\hline $\mathrm{PVDF} / \mathrm{GO}(2.0 \mathrm{wt} \%)$ & 25 & - & 64 & $\sim 80$ & {$[44]$} \\
\hline $\mathrm{PVDF} / \mathrm{rGO} / \mathrm{TiO}{ }_{2}(0.05 \mathrm{wt} \%)$ & 221 & 99 & 69 & 95 & {$[1]$} \\
\hline $\mathrm{PVDF} / \mathrm{SAPO}-34(0.5-1.0 \mathrm{wt} \%)$ & $\sim 75$ & $>98$ & 79 & $>89$ & This \\
\hline
\end{tabular}




\section{Figure captions}

Fig. 1. XRD pattern of SAPO-34.

Fig. 2. SEM images of SAPO-34.

Fig. 3. Surface SEM images of the prepared PVDF membranes with different concentrations of SAPO-34.

Fig. 4. Cross-sectional SEM images of the PVDF membranes with different concentrations of SAPO-34.

Fig. 5. Observation of SAPO-34 zeolite in the matrix of $5 \mathrm{wt} \%$ membrane.

Fig. 6. (a) EDX spectrum and (b) EDX mapping of Si element of 0.5 wt\% SAPO-34/PVDF blended membrane.

Fig. 7. Water contact angle of the prepared PVDF membranes with different concentrations of SAPO-34.

Fig. 8. Water flux (before and after BSA filtration) and BSA flux of the prepared PVDF membranes with different concentrations of SAPO-34 (after 90 min at $0.3 \mathrm{MPa}$ ).

Fig. 9. Flux recovery ratio $(F R R(\%))$ of the prepared PVDF membranes with different concentrations of SAPO-34.

Fig. 10. Fouling resistance ratio of the PVDF membranes with different concentrations of SAPO-34. 


\section{Figures}

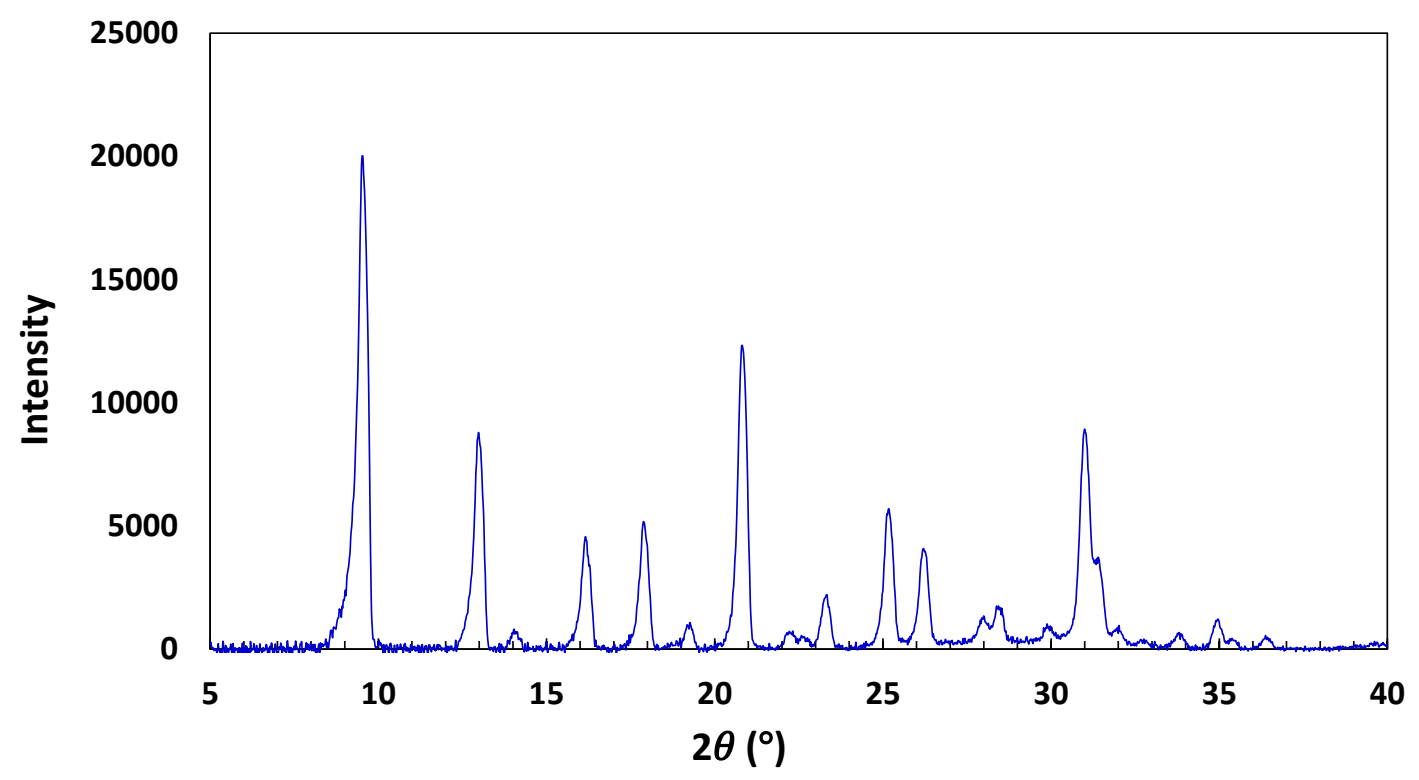

Fig. 1.

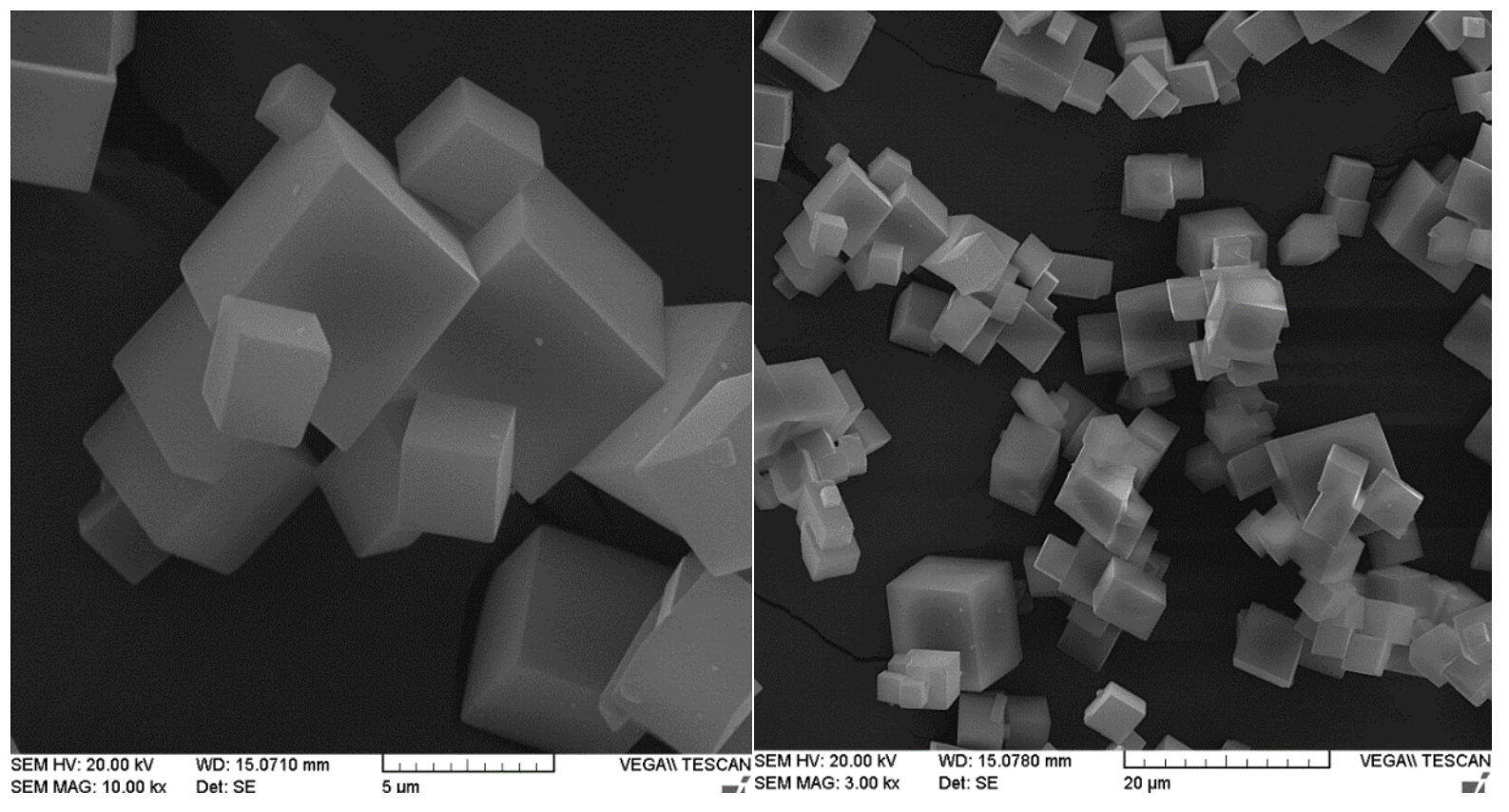

Fig. 2. 


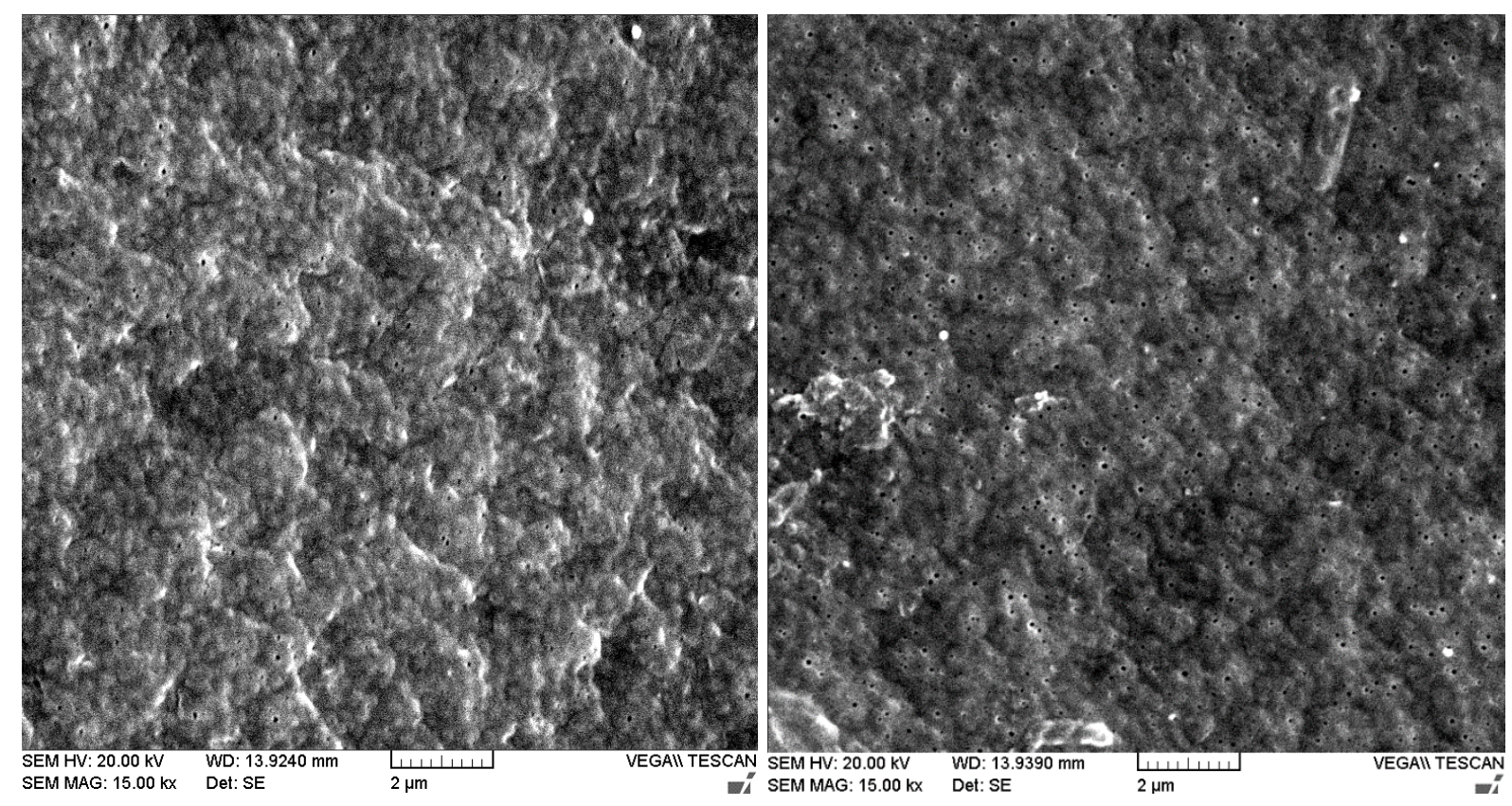

$0 \%$

$0.1 \mathrm{wt} \%$
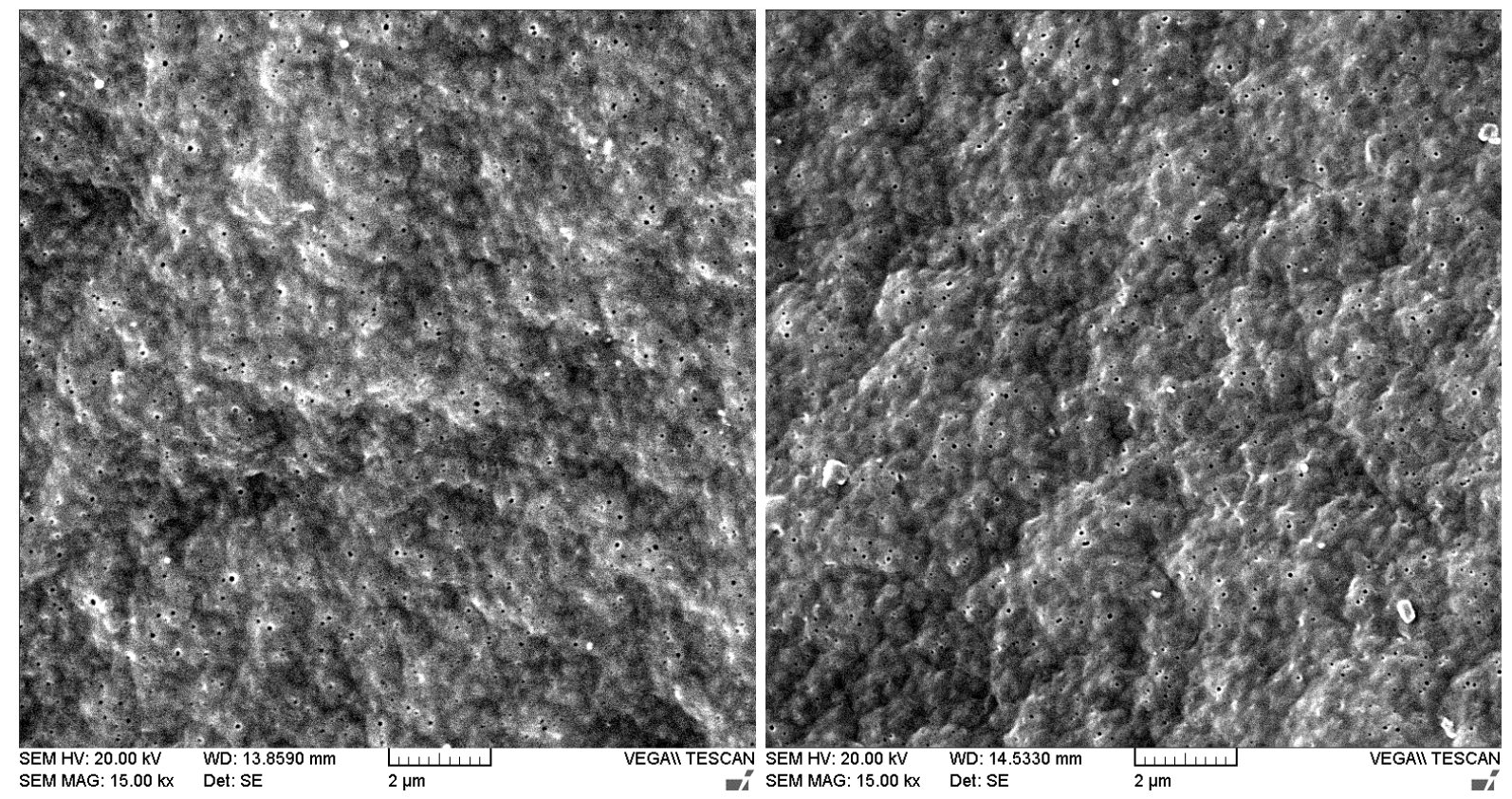

$0.2 \mathrm{wt} \%$

$0.5 \mathrm{wt} \%$ 


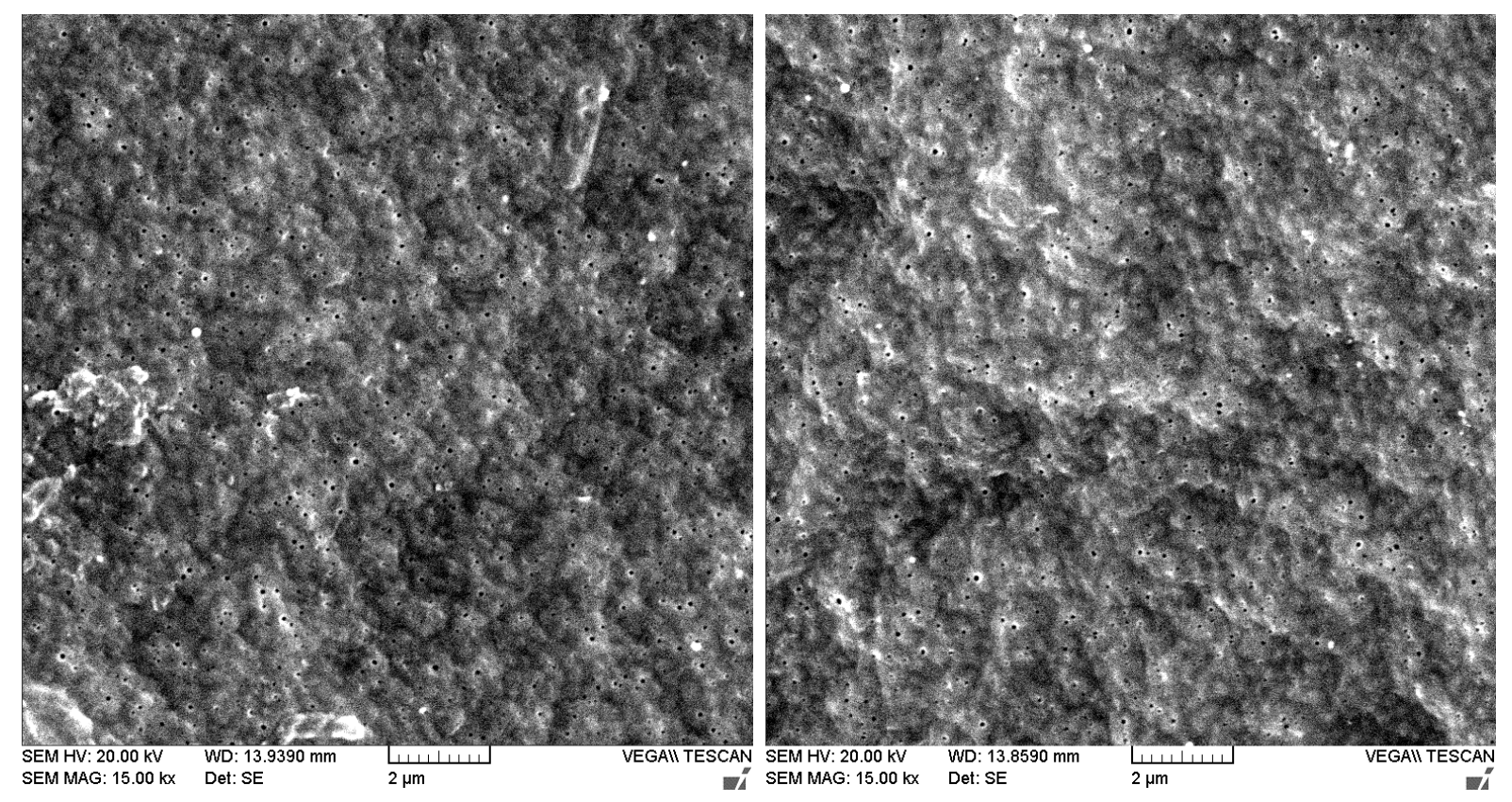

$1.0 \mathrm{wt} \%$

$2.0 \mathrm{wt} \%$

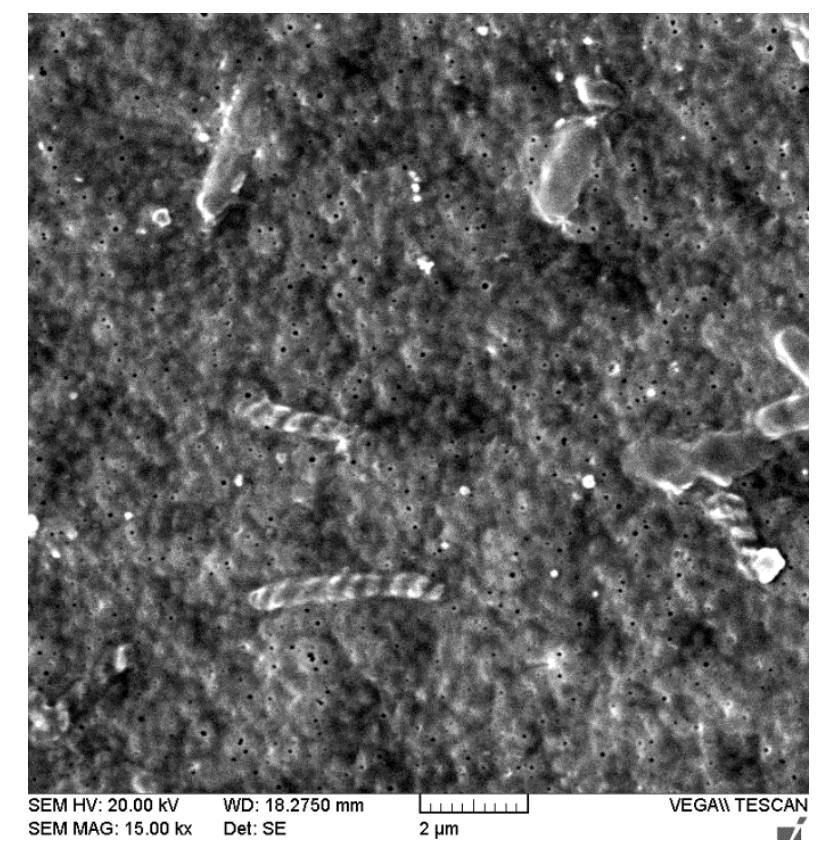

$5 \mathrm{wt} \%$

Fig. 3. 


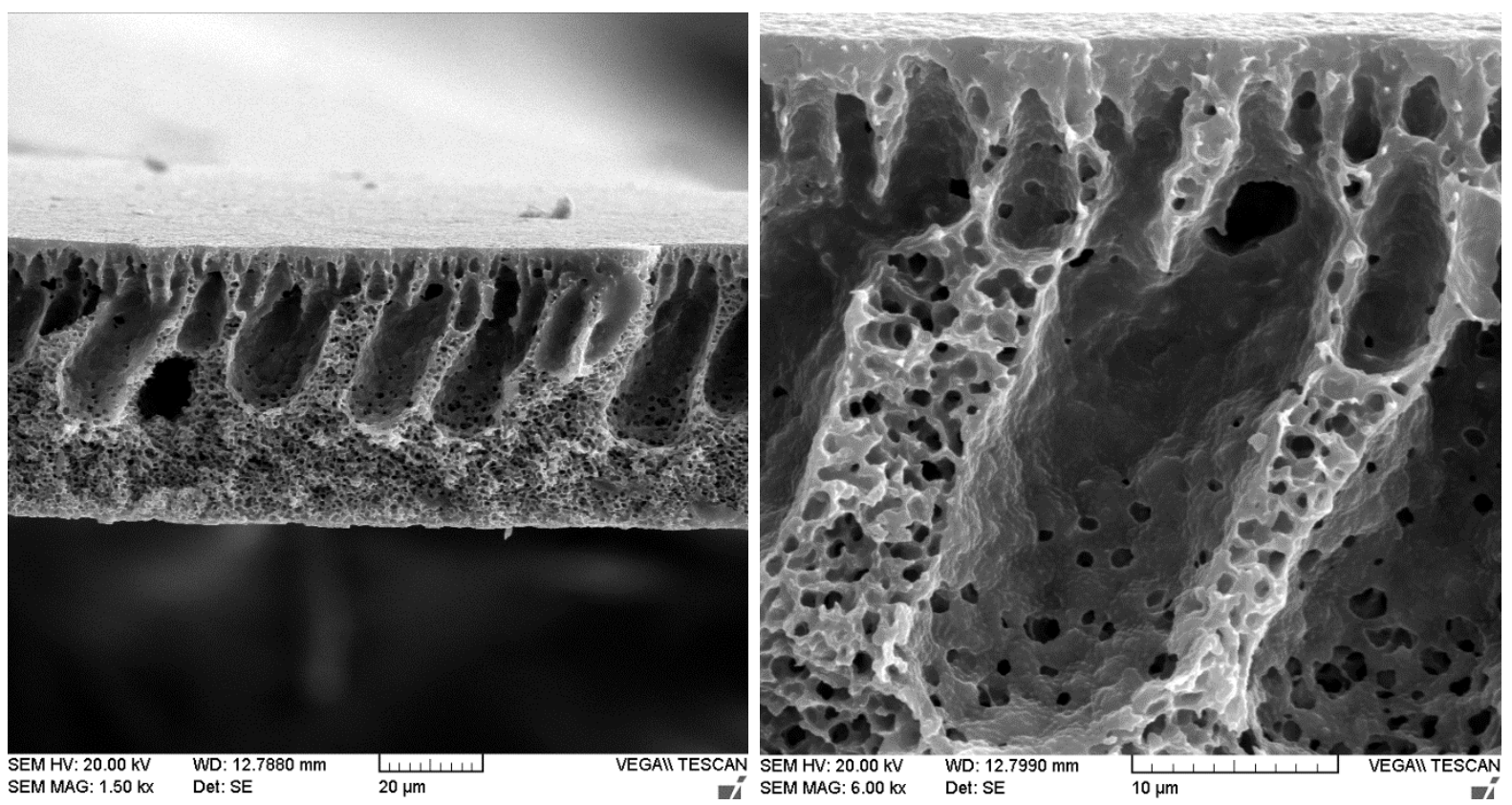

$0 \mathrm{wt} \%$

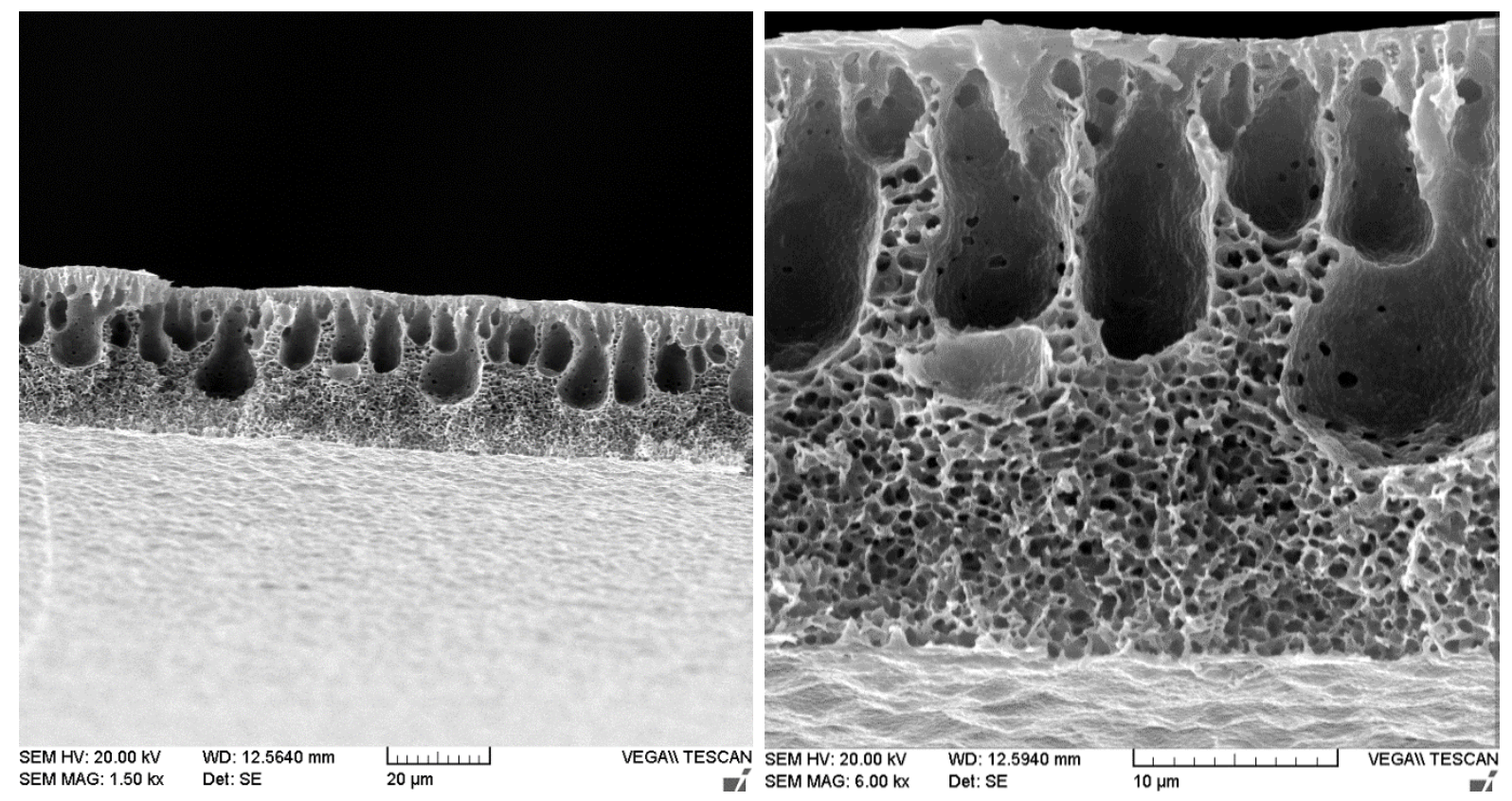

\section{$0.1 \mathrm{wt} \%$}




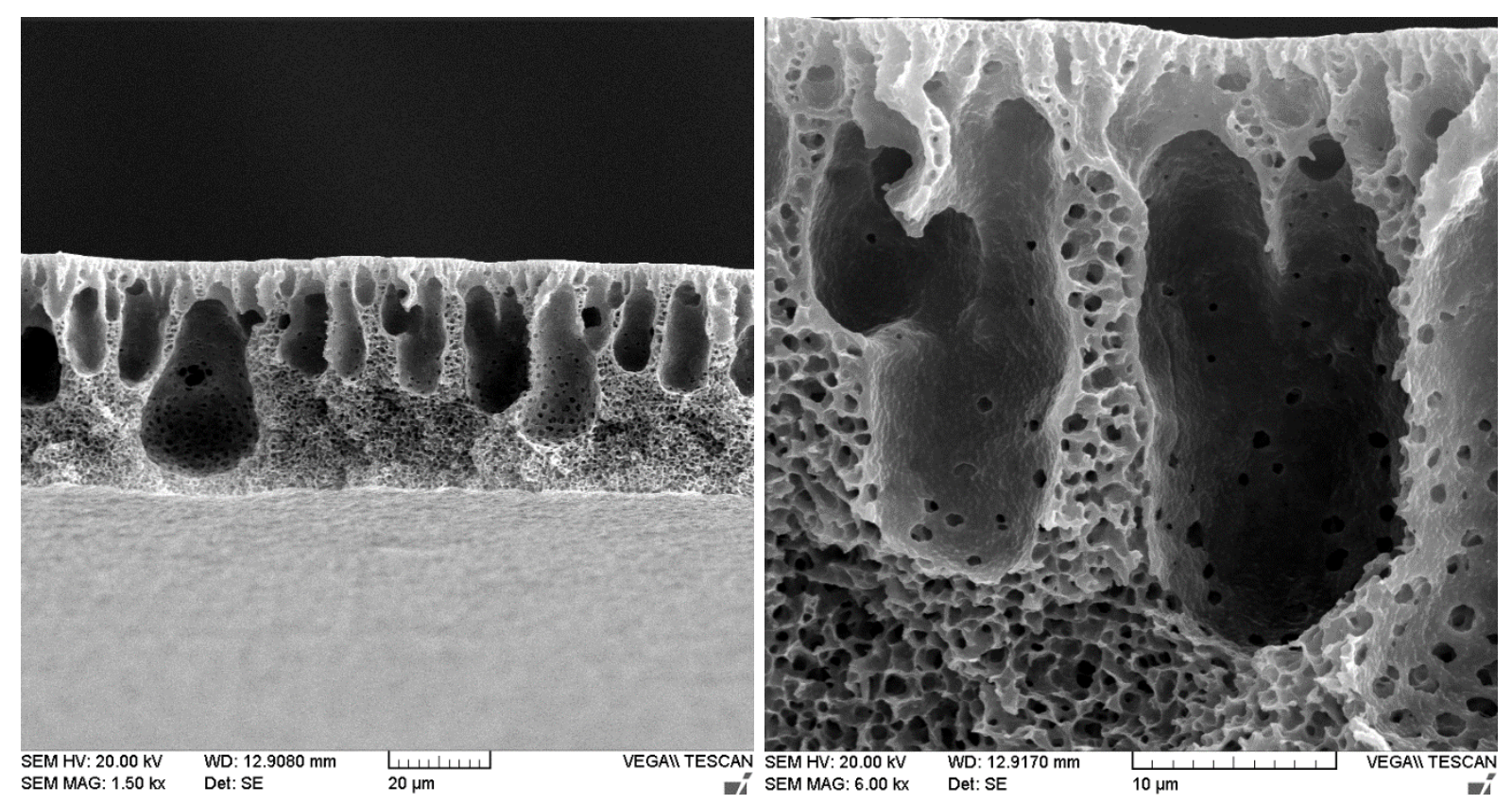

$0.2 \mathrm{wt} \%$

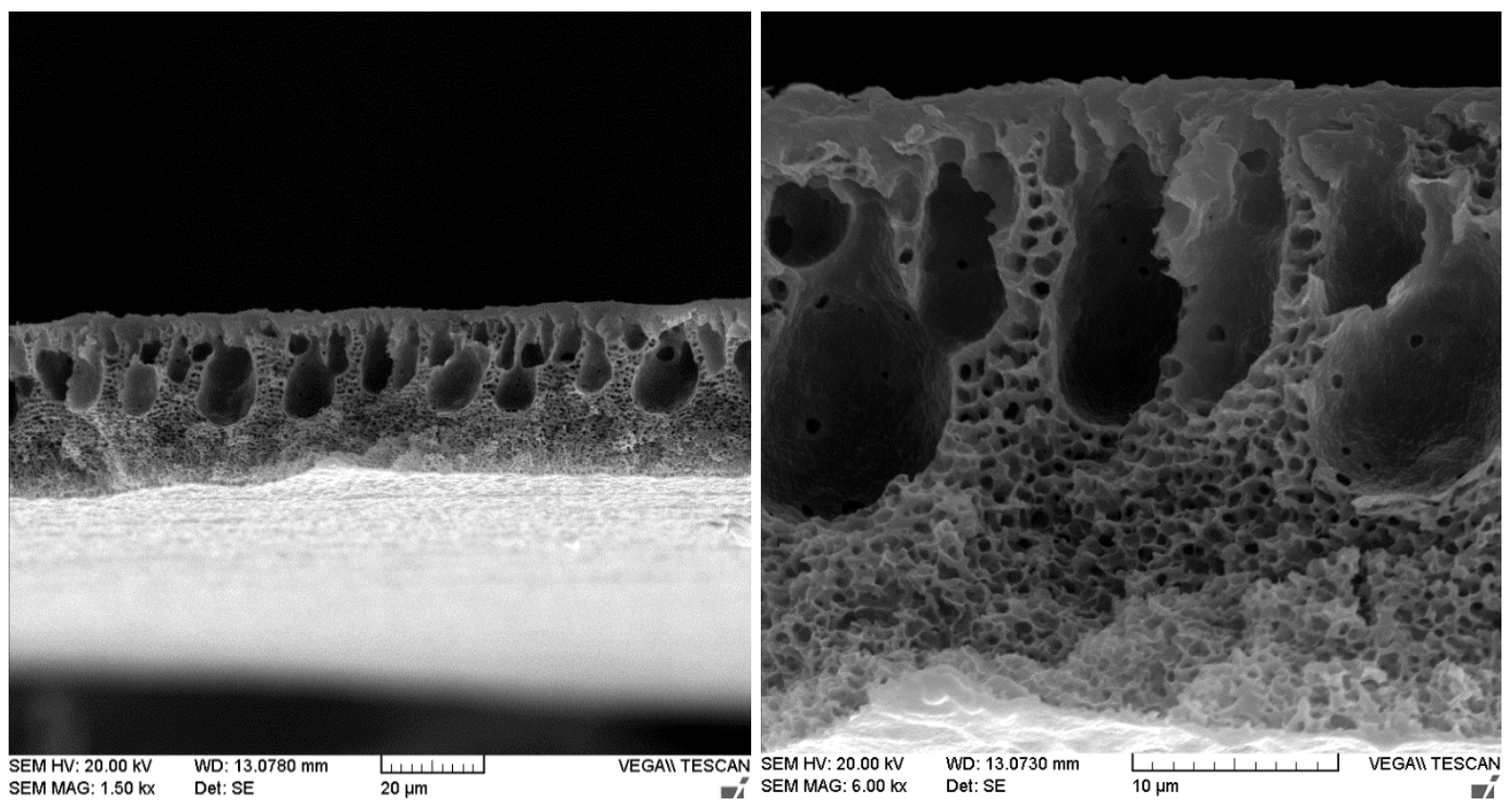

$0.5 \mathrm{wt} \%$ 


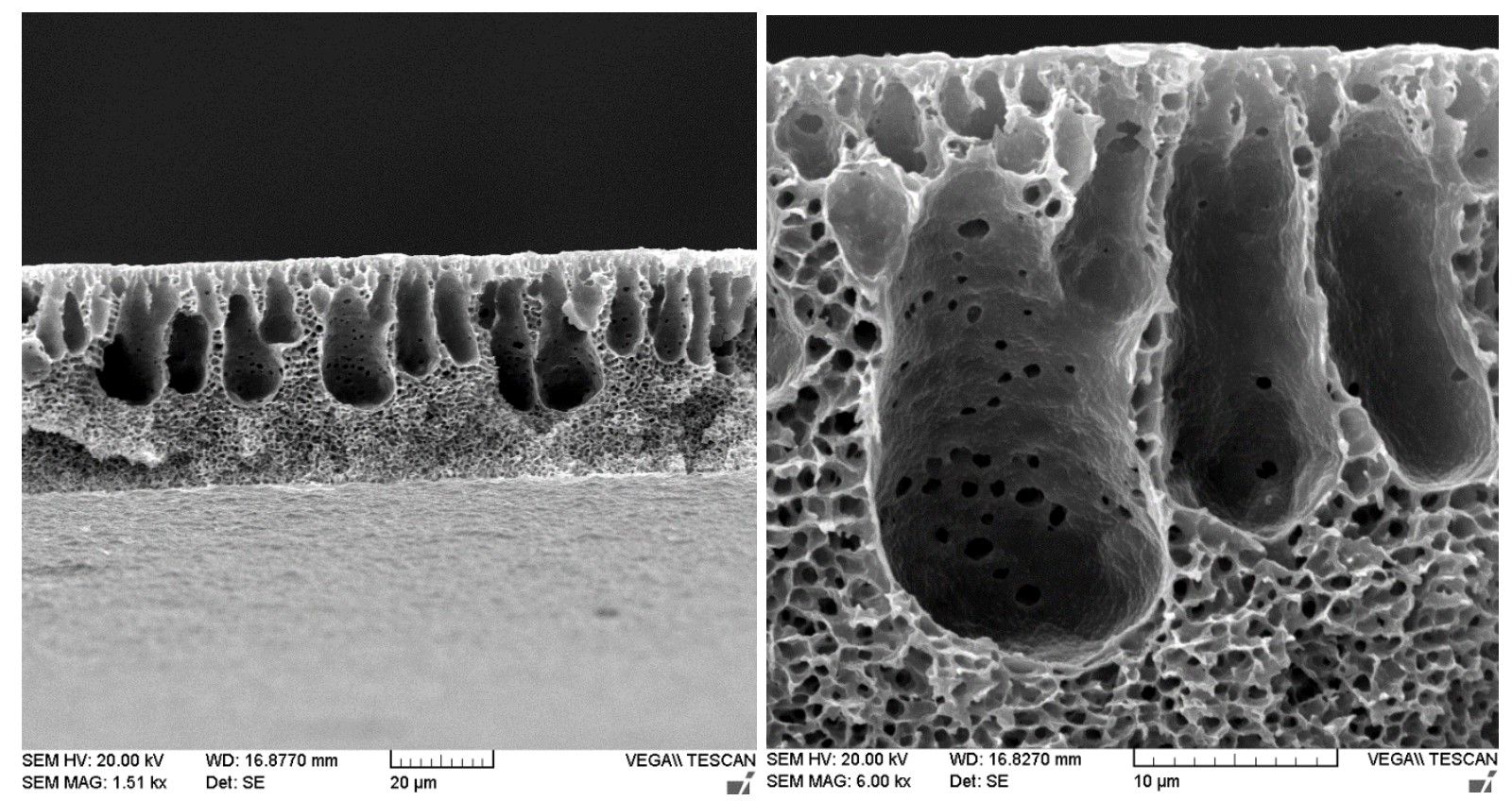

$1.0 \mathrm{wt} \%$
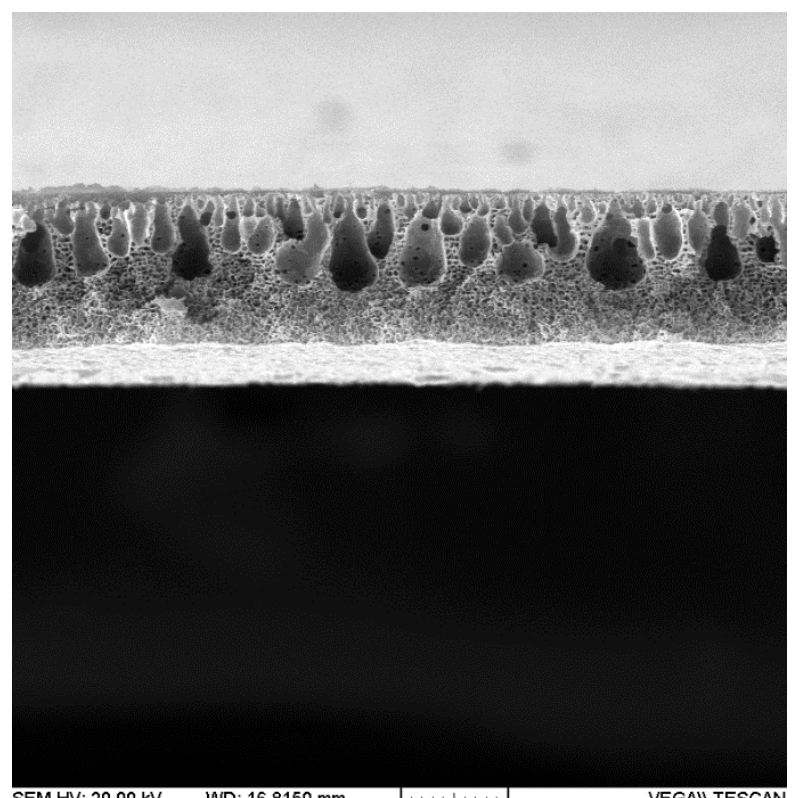

SEM MAG: $1.50 \mathrm{kx}$ Det: SE

$\frac{\mid+11}{20 \mu \mathrm{m}}$

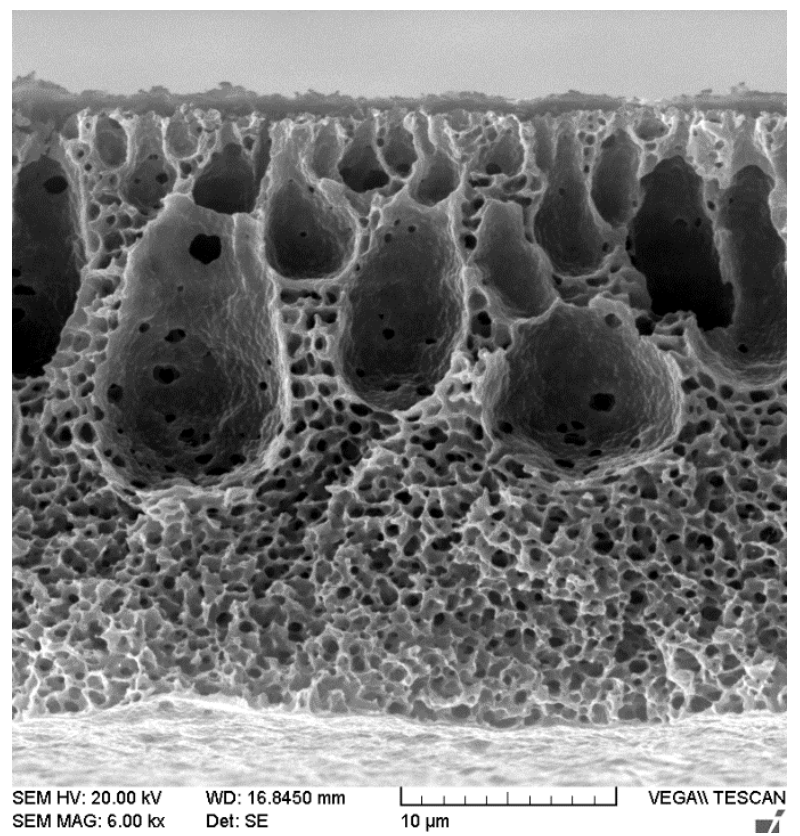

$2.0 \mathrm{wt} \%$ 


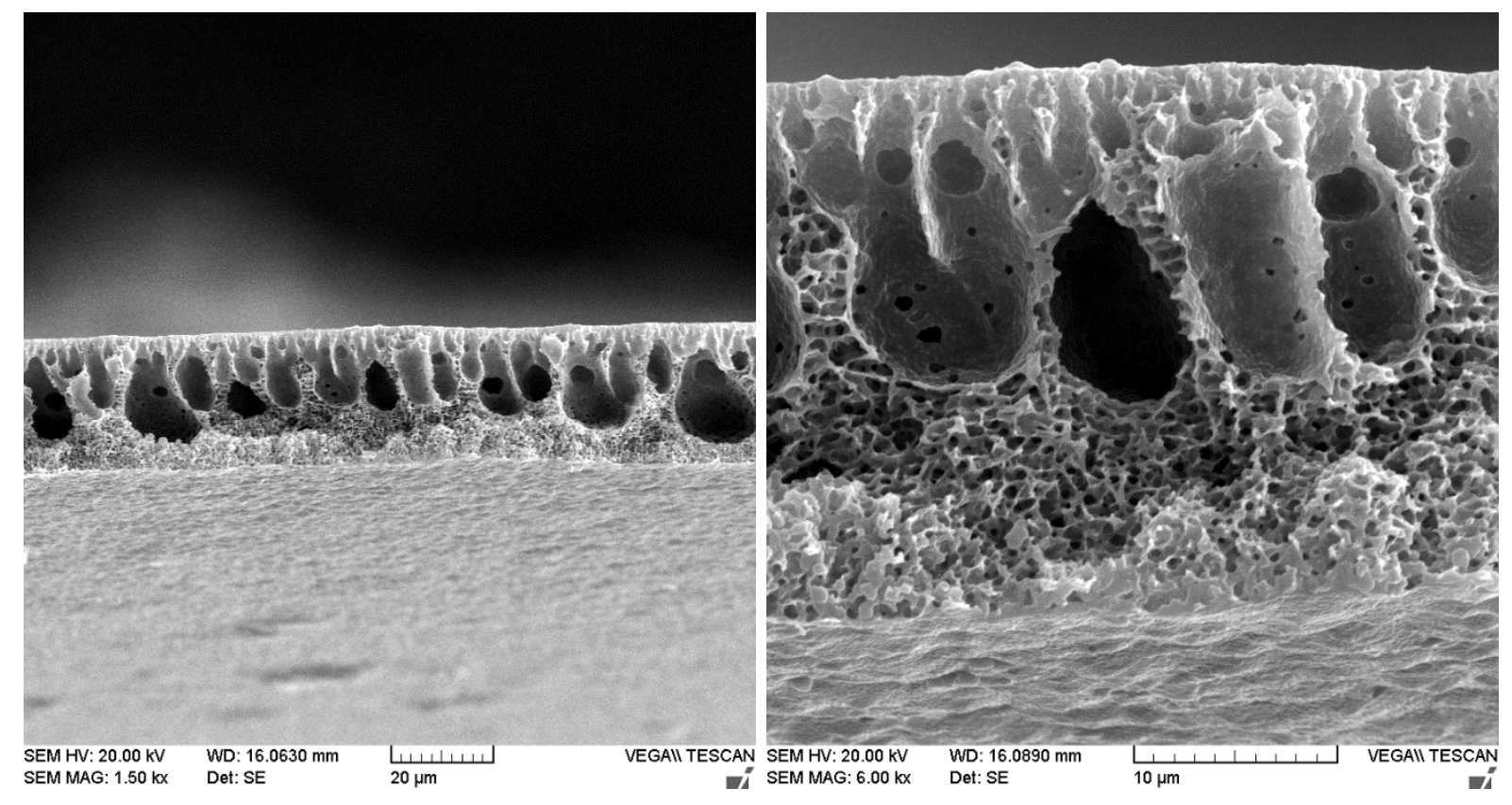

\section{$5.0 \mathrm{wt} \%$}

Fig. 4.

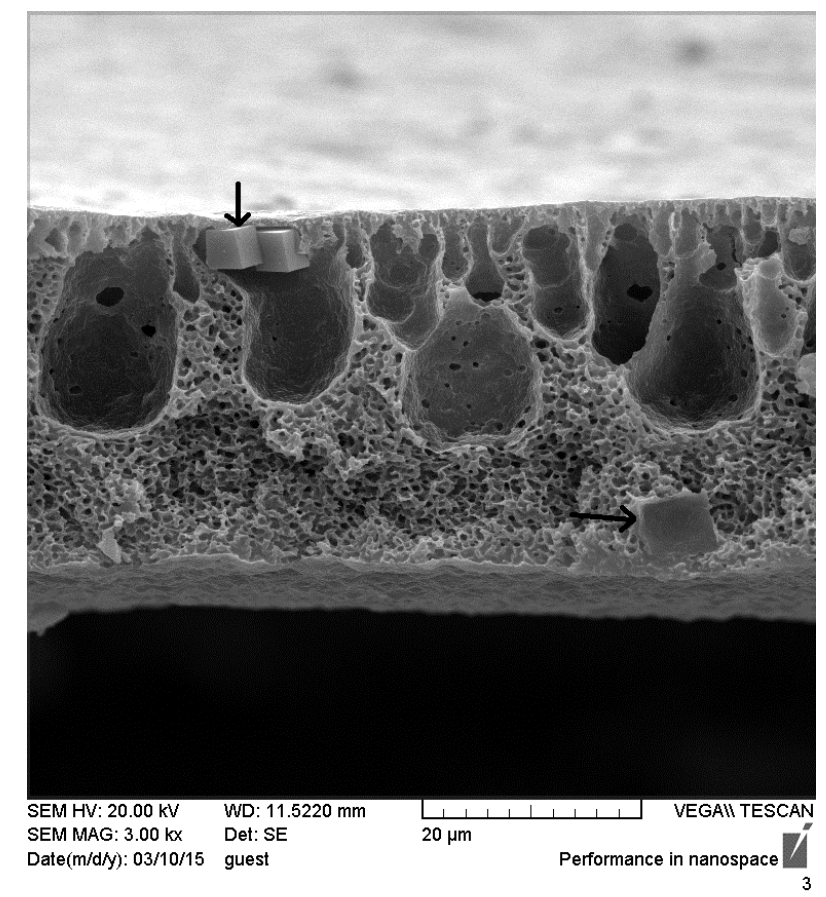

Fig. 5. 


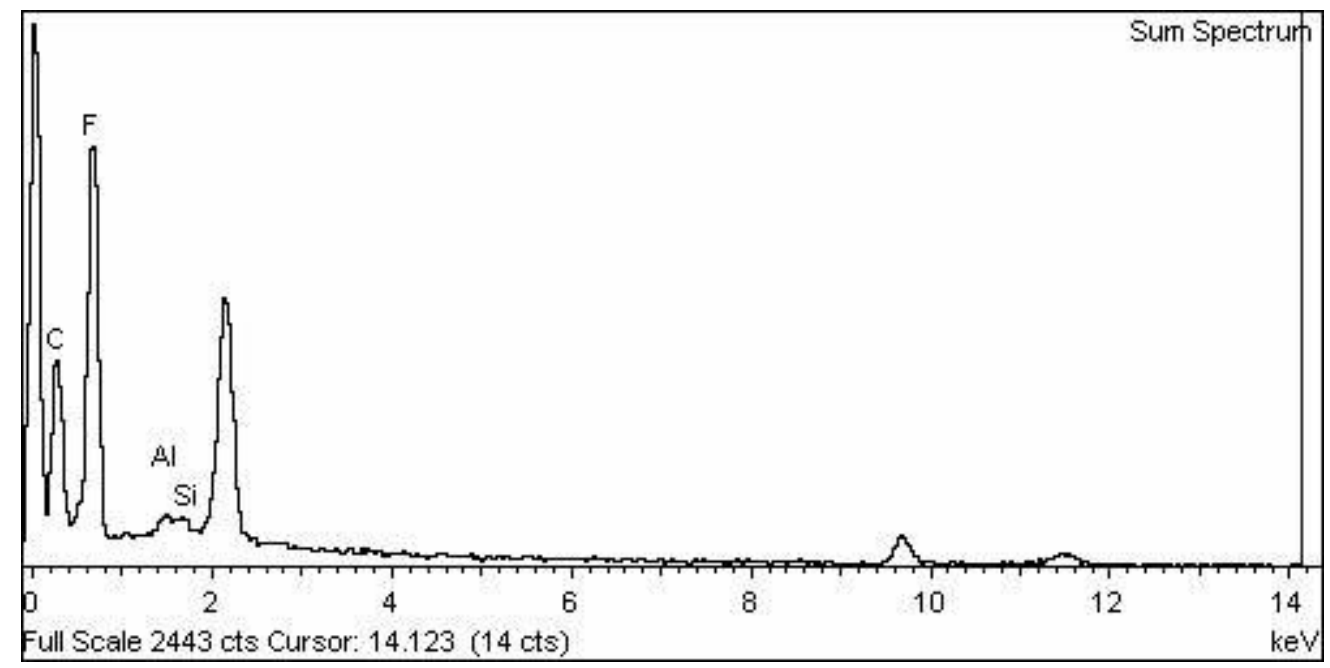

(a)

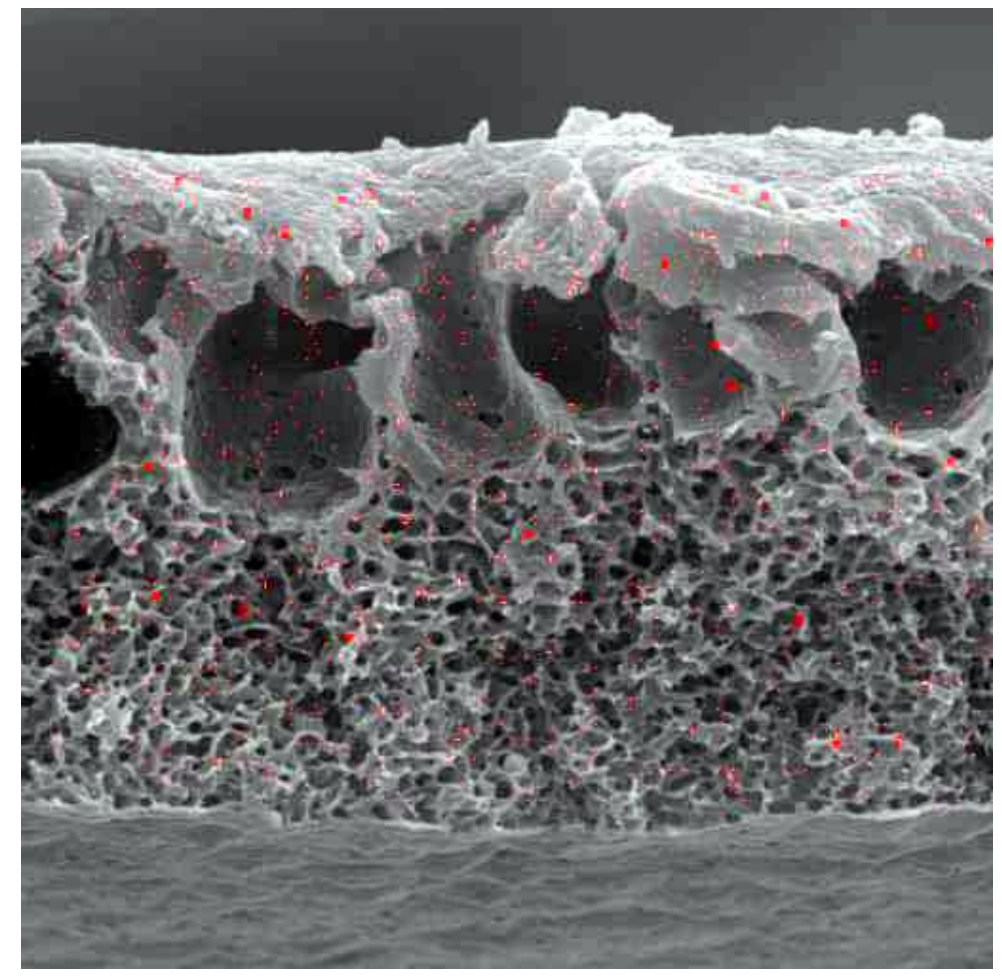

(b)

Fig. 6. 


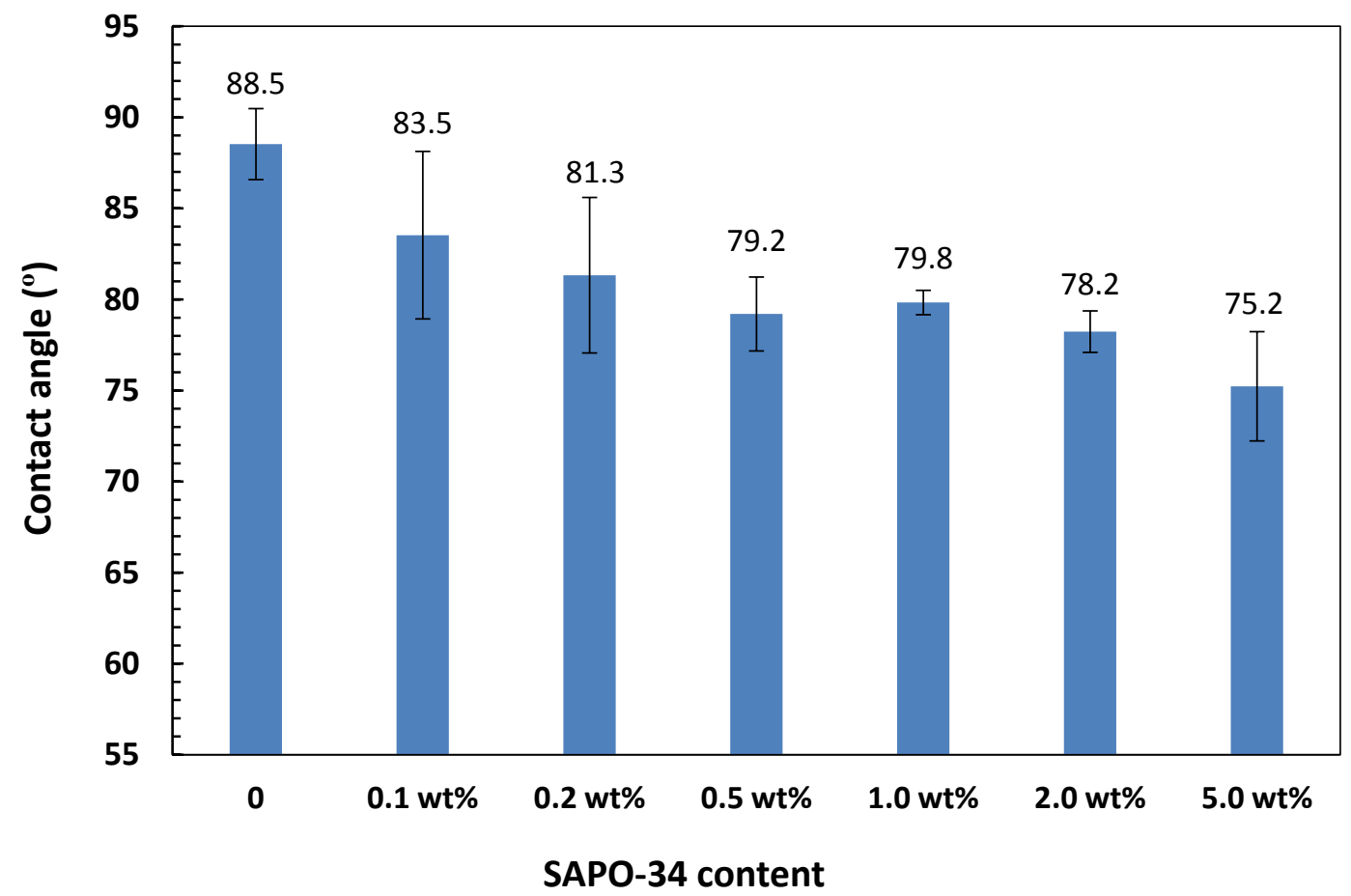

Fig. 7.

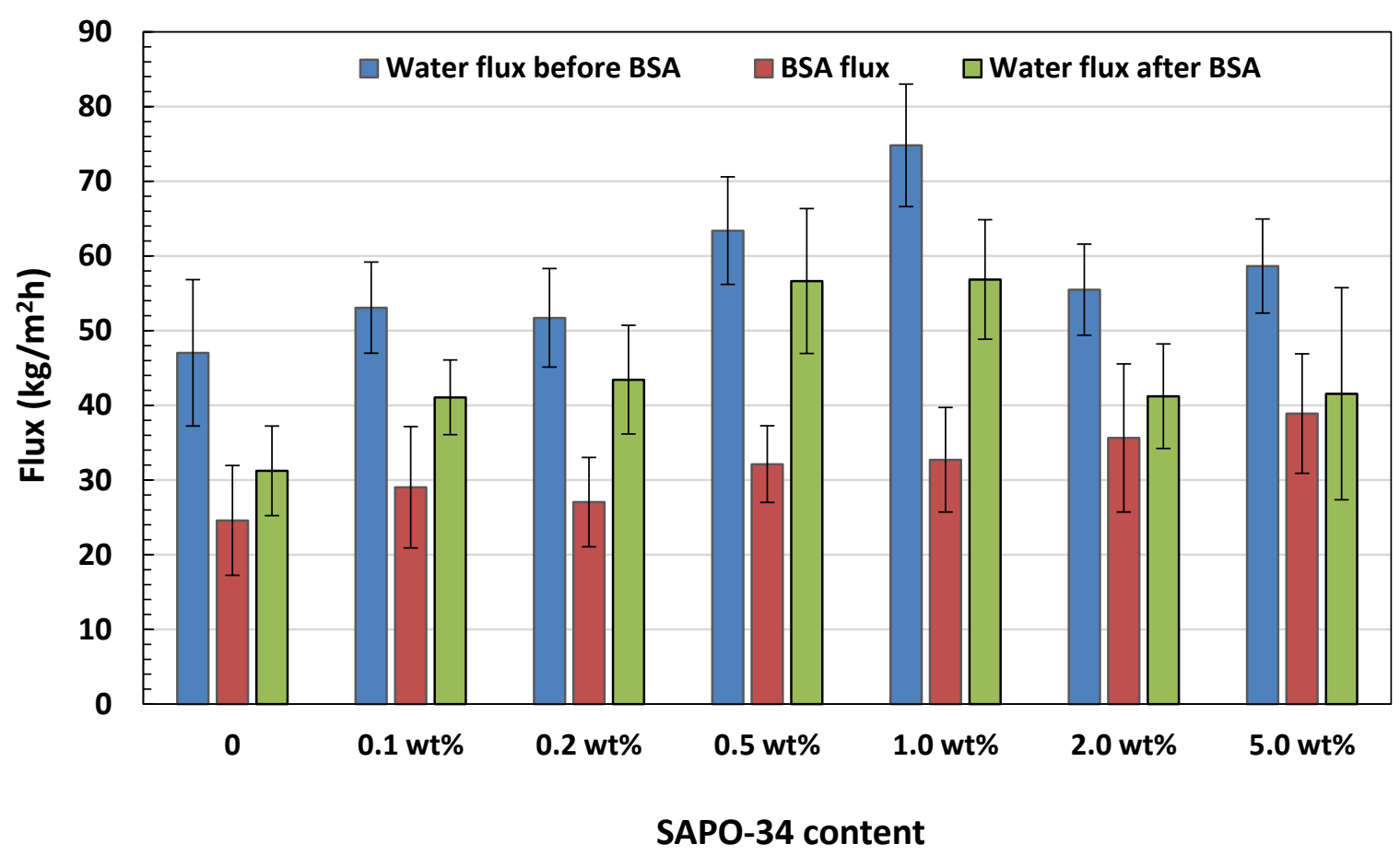

Fig. 8 . 


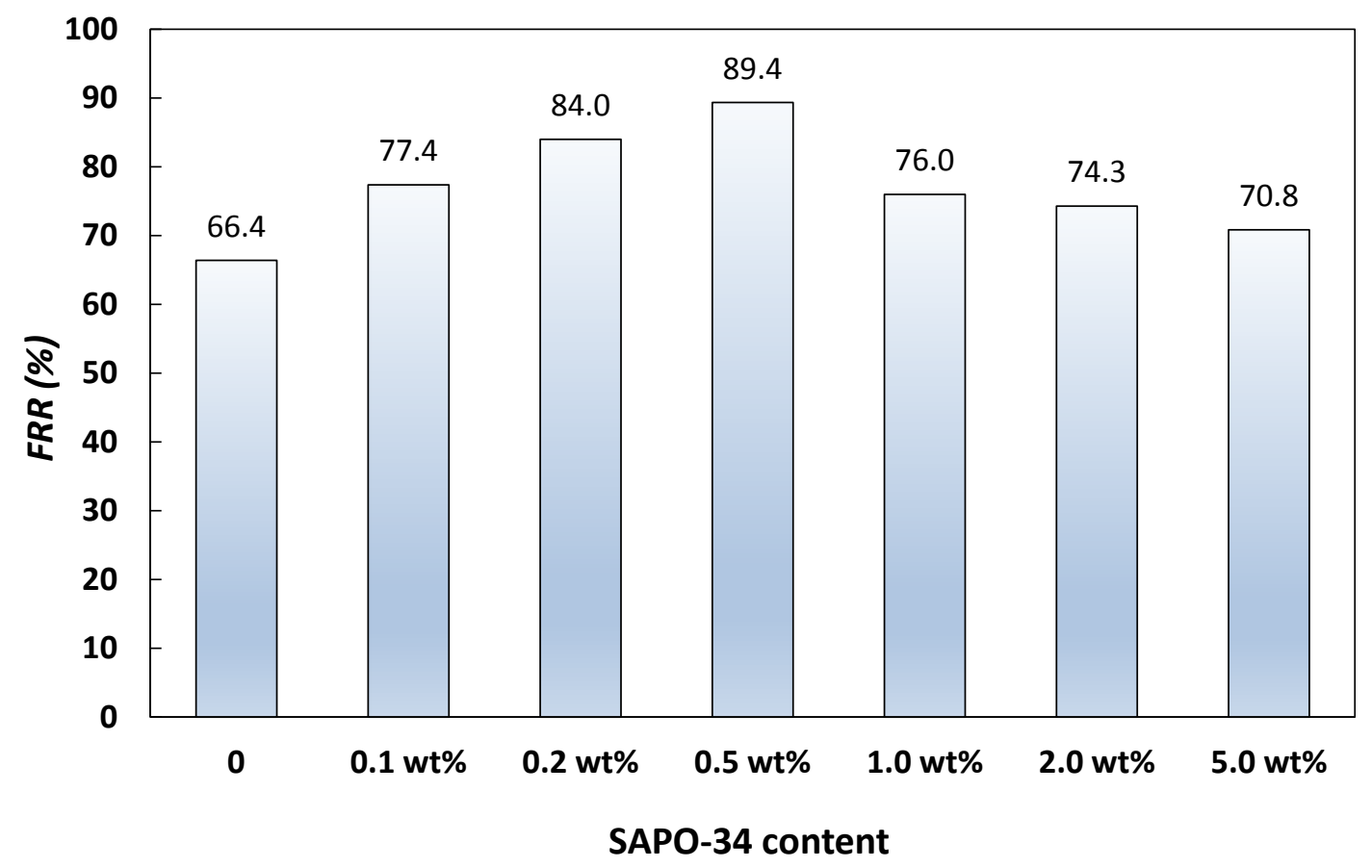

Fig. 9.

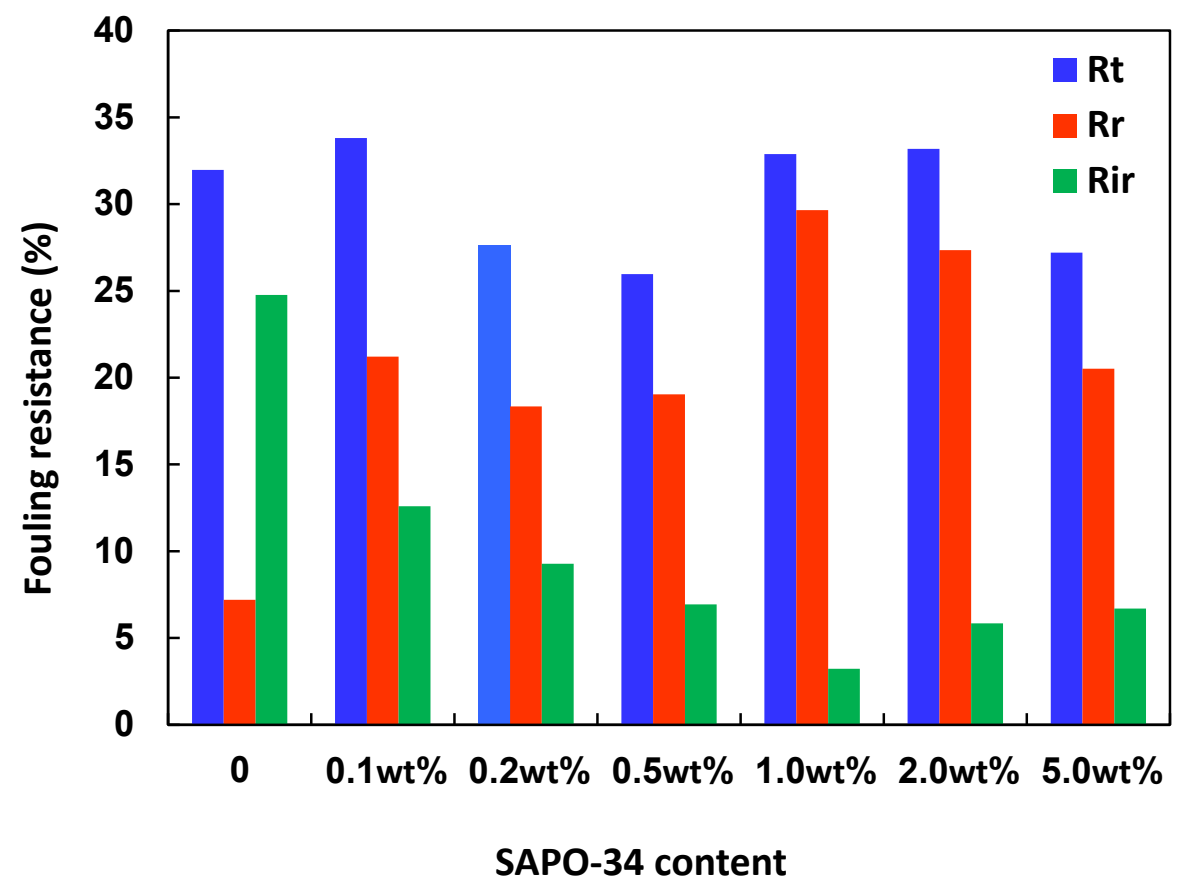

Fig. 10 . 